\title{
Low Complexity Energy Management Strategy for grid profile smoothing of a Residential Grid-Connected Microgrid using Genera- tion and Demand Forecasting
}

\author{
Diego Arcos-Aviles ${ }^{\mathrm{a}, *}$, Julio Pascual ${ }^{\mathrm{b}}$, Francesc Guinjoan ${ }^{\mathrm{c}}$, Luis Marroyo ${ }^{\mathrm{b}}$, Pablo Sanchis ${ }^{\mathrm{b}}$, Martin P. \\ Marietta ${ }^{c}$ \\ ${ }^{a}$ Departamento de Eléctrica y Electrónica, Propagation, Electronic Control, and Networking (PROCONET) Research Group, Uni- \\ versidad de las Fuerzas Armadas ESPE. Av. Gral. Rumiñahui s/n, 171-5-231B, Sangolquí, Ecuador \\ ${ }^{\mathrm{b}}$ Department of Electrical and Electronics Engineering, Public University of Navarre (UPNa). Edificio de los Pinos, Campus Arro- \\ sadia s/n, 31006, Pamplona, Spain.

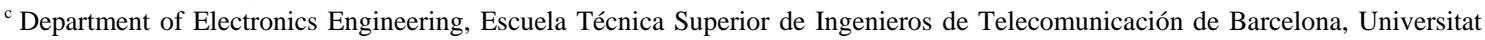 \\ Politècnica de Catalunya. C. Jordi Girona 31, 08034, Barcelona, Spain. \\ * Corresponding autor. Tel.: +593994490050 \\ E-Mail address: dgarcos@espe.edu.ec (D. Arcos-Aviles)
}

\begin{abstract}
This paper presents the design of an energy management strategy based on a low complexity Fuzzy Logic Control (FLC) for grid power profile smoothing of a residential grid-connected microgrid including Renewable Energy Sources (RES) and battery Energy Storage System (ESS). The proposed energy management strategy uses generation and demand forecasting to anticipate the future behavior of the microgrid. According to the microgrid power forecast error and the Battery State-of-Charge (SOC) the proposed strategy performs the suitable control of the grid power minimizing fluctuations and power peaks in the power profile exchanged with the grid while keeping the energy stored in the battery between secure limits. A comparison with previous energy management strategies is presented at simulation level to highlight the advantages of the proposed strategy. Finally, the features of the new design are experimentally tested on a real residential microgrid implemented at the Public University of Navarre (UPNa, Spain) achieving a smooth grid power profile and a battery SOC center close to the $75 \%$ of the rated battery capacity.
\end{abstract}

\section{Keywords}

Distributed power generation

Energy management

Power forecasting

Fuzzy control

Microgrid

Power smoothing 


\section{Introduction}

The benefits that Renewable Energy Sources (RES) (e.g., photovoltaic, wind turbines...) have exhibited in the last years, such as reducing the fuel consumption and the Greenhouse Gases (GHG) emissions [1], have contributed to the development of Distributed Generation (DG) systems to become a competitive solution for future power systems (i.e., Smart Grids) [2], since they can produce electrical power with less environmental impacts, they are easy to install, and they are highly efficient with increased reliability $[3,4]$. However, the integration of the utility grid with DG systems in a distributed, efficient, and reliable manner without excessive investment still remains a challenge [5].

The Microgrid (MG) concept is a quite appealing alternative for overcoming the challenges to integrate Distributed Energy Resources (DER) units, including RES, into power systems [6,7], and they have emerged as an integral feature for the upcoming power systems shaped by the various Smart Grid initiatives [8-13]. In general, MGs are defined as low-voltage distribution network comprising loads, DG units, and Energy Storage System (ESS) (e.g., batteries, flywheels, ultra-capacitors...) that are capable of operating in both grid-connected and stand-alone modes [9,11]. The electrical connection of these elements constitute the MG power architecture which, in turn, can be connected to the mains at a single Point of Common Coupling (PCC) [10,14]. The Energy Management System (EMS) is the heart of the MG and is in charge to drive the controllable elements of the MG (i.e., those sources, loads, and storing elements which can be controlled) to reach a set of pre-defined goals depending on the operation mode [15].

In the case of stand-alone microgrids, where the MG is separated from the distribution network, the main goal of the EMS is keeping a reliable power supply to the customer, limiting the power output when necessary and sometimes using demand side management (DSM) techniques in order to avoid battery depletion $[16,17]$. In addition, when dispatchable power units are presented in the MG, another goal is usually to reduce operating costs by optimally scheduling the different dis-patchable units in the system, using different optimization routines, as seen in [18-21].

However, in the case of grid-connected mode where this work focuses on, the grid, which can act as power source or a power sink, assures the reliable power supply to consumer. In this case, the EMS has to control the power flow among the MG elements to reach a set of predefined objectives such as minimizing the MG operating costs [22,23] or maximizing the revenues according to DG bids and electricity market price [15]. The energy management strategy design should take into account the MG power architecture and, in particular, the power management capability of the elements within the MG (i.e. which sources, loads and storage elements can be controlled). Once the power architecture and the predefined objectives are known, the energy management strategy design can be undertaken by applying different methods $[4,6,8,24-28]$. In this regard, there is a wide variety of works handling different scenarios in terms of power architectures, objectives, and methods.

For instance, in [29] an energy management strategy is designed using local prediction and local forecasting as well as Stochastic Dynamic Programming (SDP) to control and extend the lifetime of an ESS included in a grid-connected MG with diesel and renewable generators. In [30] a predictive control technique is applied in a grid-connected MG to manage the ESS power to compensate hourly deviations based on a forecasted energy plan. Other studies consider scenarios with more degrees of freedom where the energy management strategy drives different storage elements (e.g., batteries, fuel cells...), controllable loads (e.g., electrical load management, heat pumps...) or a combination of both, as in [31-34], to carry out Demand Side Management (DSM) and Demand Response (DR) strategies, where the control methods used in those cases are usually sophisticated as Model Predictive Control (MPC) and, include both generation and demand forecasting as in $[35,36]$.

Alternatively to these analytically-based control methods, Fuzzy Logic Control (FLC) allows the implementation of the human's heuristic knowledge about how to control a system $[37,38]$ and has also been applied to the EMS design. For instance, in [39] a FLC-based EMS is designed to prioritize selling the additional electricity generated by RES and to maintain the battery State of Charge (SOC) above the $50 \%$ to extend the ESS lifetime, whereas in [40,41] a rule-based controller (i.e., FLC) is used in combination 
with different optimization techniques to achieve an optimum energy cost and thermal comfort in grid connected microgrids.

From the literature review it can be noticed that most of the EMS designs for grid-connected mode, are focused on the MG economic profitability paying less attention on the resulting power profile exchanged between the MG and the grid. However, economic incentives and penalties set by grid operators are a reflection of technical issues such as line congestion or grid stability [42]. For this reason, this paper focuses directly on minimizing the fluctuations and power peaks of the power profile exchanged with the mains, as in [30,32,42-52]. Smoothing the grid power profile can be considered a suitable solution in a residential MG scenario, since it facilitates the grid operators control and, consequently, the penetration of RES into the distribution network. Moreover, the grid power profile control allows residential consumers to generate their own energy resulting in a decrease of the amount of energy consumed from the utility grid, thus, reducing their electricity bill [53]. In this regard, the studies developed in [32,34,42,44-51] focus on a very restrictive residential grid-connected microgrid with only a single controllable element (battery charger/inverter, see next section) and address the power profile control of the power exchanged with the mains.

The earliest approach to smooth the grid power profile was the use of the Simple Moving Average (SMA) filter with a window size of one day [44]. This filter splits the high- and low-frequency components of the net power (difference between the load and the generated power) of the MG which are respectively handled by the ESS and the mains. The main drawback of SMA filtering is the filter delay itself: for instance, if several consecutive days of high irradiance leading to a power delivery from the MG to the mains are followed by a cloudy day, the MG delivers to the grid more power than the power that would correspond to the new energy conditions. This situation would prevail until the window of the SMA filter is only filled with the values of the new conditions, which takes 24 hours. As a result, the ESS fall into over discharge and the system loss the control of the grid power who take the shape of the net power. For this reason, a second approach adds the battery SOC as an additional control loop [45] to keep the ESS between secure limits. The way of designing this control loop is based on simple analytical functions to limit the battery SOC variation, which parameters are heuristically adjusted. This way, the SOC range is preserved but at the expense of introducing high fluctuations in the grid power.

Taking advantage of the aforementioned heuristic approach, and with the aim of improving the grid power profile smoothness, several low-complexity FLC-based EMS detailed designs inspired in [45] were presented in $[46,49,51]$ considering different input variables (i.e., control loops). Finally, an improved design of two inputs, one output low-complexity FLC of only 25 rules, experimentally validated in [47], led to a noticeable improvement in the grid power profile smoothness. The key factor of this improved design was to anticipate the MG future behavior by means of including the MG Energy Rate-of-Change (ERoC) (i.e., the derivative of SMA filter output) as an input of the FLC. This way, the grid power profile starts to be modified as soon as the MG power balance average value started to change. This enhanced behavior allowed a quick reaction of the energy management strategy against sudden MG energy changes to set the battery SOC close to the $75 \%$ of the rated battery capacity and to concurrently smooth the grid power profile. In fact, this new input mitigated the SMA delay effect.

In [42], making use of generation and demand forecast, the SMA filter is converted into a Central Moving Average (CMA). This way, the grid power profile is modified to meet the new MG energy state even before it occurs. This approach, however, is subject to the accuracy of the forecasted data. By means of using the cumulative forecasting error and the battery SOC the authors propose a control loop to limit the grid power fluctuations and to preserve the SOC within secure limits in front of forecasting errors. This strategy leads to a better grid profile with the same battery system. However, and as in [32], this control loop is based on analytical functions with parameters adjusted heuristically.

To improve the results obtained in [42], this paper propose a FLC-based EMS including generation and demand forecasting which anticipates the MG future behavior to smooth the power profile exchanged with the grid. As in [42], the FLC-EMS uses a CMA filter instead of SMA one to avoid making decisions based on the MG power balance of the preceding 24-hours. To limit the power fluctuations due to fore- 
casting errors tis work suggests a control loop based in two control blocks, namely: the first one is based on a low-complexity FLC design of two-input, one output, and 25 rules, which takes into account the power forecasting error and the battery SOC with the purpose of controlling the power delivered/absorbed by the mains. The second block is based on a battery SOC control, which modifies the grid power profile according to the 24-hours SOC average value.

The advantages of the proposed approach with respect to other energy management strategies lie in the simplicity of its implementation and the improvement of the grid power profile quality. In particular, the proposed design performs less SOC excursion range, less peak value of the power interchanged with the grid and less value of the maximum grid power derivative. A comparison with previous strategies is presented at simulation level, whereas the features of the proposed approach are validated in a real MG installed at Public University of Navarre (UPNa, Spain).

The rest of the paper is organized as follows. Section 2 describes the residential MG configuration, the general control policy, and the performance indicators to quantify the power profile smoothing. The proposed FLC energy management strategy design is presented in Section 3. Section 4 details the simulation comparison results according to the performance indicators. In Section 5, the experimental validation of the proposed strategy is presented. Finally Section presents the main conclusions of this study.

\section{Residential microgrid configuration and control policy}

\subsection{System description}

The architecture under study is a residential grid-connected MG with a Hybrid Renewable Energy System (HRES), domestic load, and ESS as shown in Fig. 1. The HRES includes a Photovoltaic generator (PV) of $6 \mathrm{~kW}$ and a small Wind Turbine (WT) of $6 \mathrm{~kW}$, the domestic AC load comprises typical electrical loads (e.g., electrical appliances, lighting ...) with a rated power of $7 \mathrm{~kW}$, and the ESS involves a lead-acid battery bank with $72 \mathrm{kWh}$ rated capacity [48].

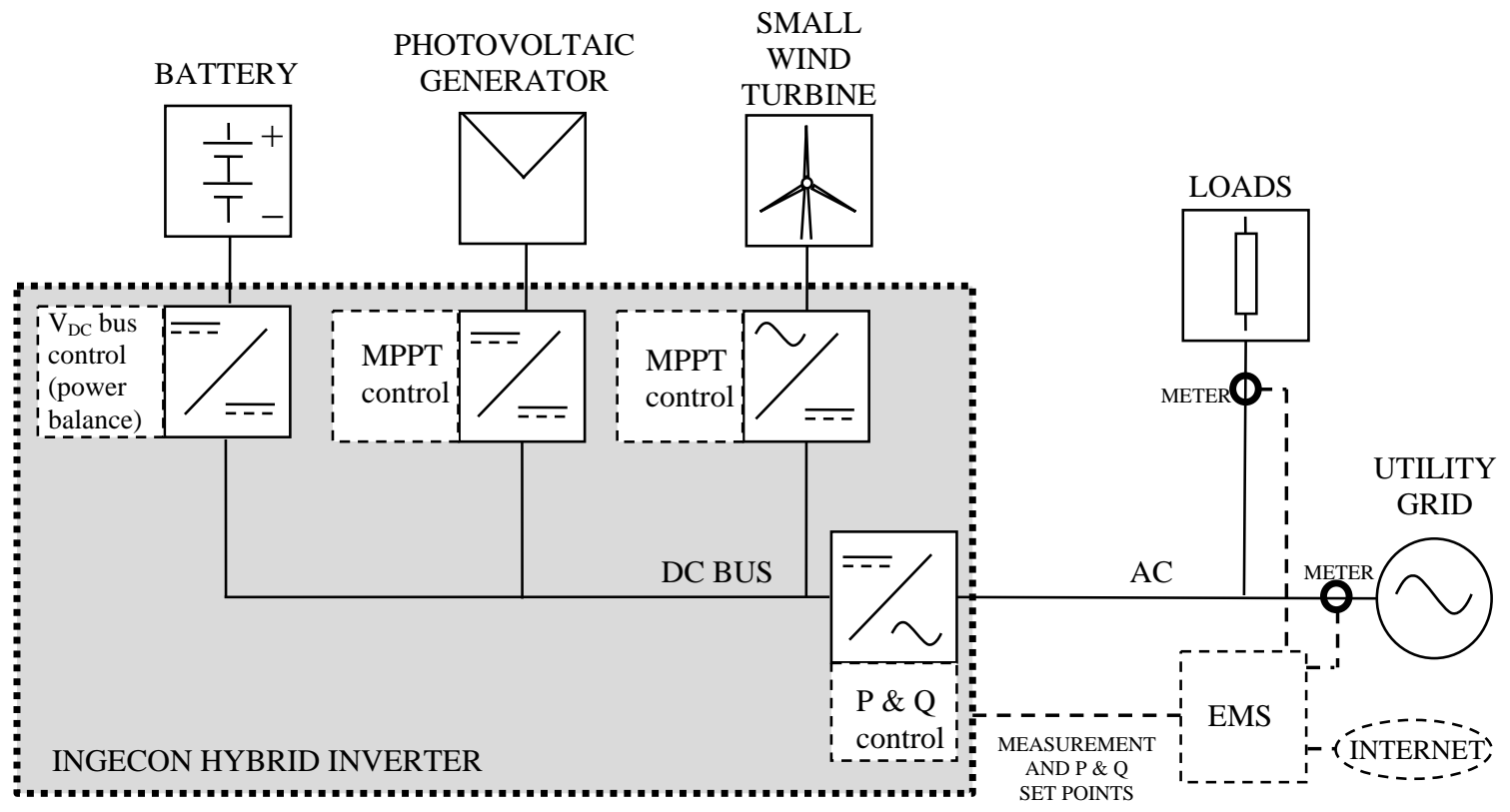

Fig. 1. Residential grid-connected microgrid architecture under study.

From Fig. 1, on the supply side, $P_{P V}$ and $P_{W T}$ represent the photovoltaic and wind power generation, respectively; $P_{B A T}$ represents the power delivered/absorbed by the battery; and, $P_{G R I D}$ represents the power delivered/injected by/to the mains. On the demand side, $P_{L O A D}$ stands for the load power demand required by electric loads. In addition, the power variables shown in Fig. 1 are considered positive when the power flows according to the direction of the corresponding arrows. Therefore, $P_{P V}, P_{W T}$, and $P_{L O A D}$ are always 
positive, whereas $P_{B A T}$ and $P_{G R I D}$ are considered positive when the battery and the utility grid inject power to the MG. Conversely, $P_{B A T}$ and $P_{G R I D}$ are considered negative when they absorb power from the microgrid.

The hybrid power converter used in this work (INGECON® Hybrid Inverter) includes a wind turbine power conversion module, a battery charger and photovoltaic power conversion module, and a bidirectional inverter-rectifier module for controlling the power exchanged with the grid. The battery charger has an internal active power control whereas the power inverter includes an active and reactive power control within it. As shown in Fig. 1, the energy management strategy concurrently provides the reference value of the active power of both converters (i.e., battery charger and inverter) and the reactive power of the inverter. In this regard, as the reactive power does not have associated energy, the bidirectional inverterrectifier can supply all reactive power of the load as long as the apparent power does not exceed its the nominal value. In order to do that, the energy management strategy measures the reactive power of the load and gives it as reference value to the inverter-rectifier.

From the configuration shown in Fig. 1, the power exchanged with the grid is expressed as:

$$
P_{G R I D}=P_{L G}-P_{B A T} \text {, }
$$

where $P_{L G}$ is the MG net power, which is defined as the difference between load power demand, $P_{L O A D}$, and renewable power generation, $P_{G E N}$, as follows:

$$
\begin{gathered}
P_{L G}=P_{L O A D}-P_{G E N}, \\
P_{G E N}=P_{P V}+P_{W T},
\end{gathered}
$$

being $P_{G E N}$ the MG renewable power generation.

Note that the case under study assumes that PV and WT are working at Maximum Power Point (MPP) and the load power consumption is not controllable (i.e., $P_{L O A D}, P_{G E N}$, and $P_{L G}$ cannot be controlled). In contrast, the grid power profile, $P_{G R I D}$, will be controlled by a bidirectional inverter-rectifier, whereas the battery charger will handle, if able to, the resulting battery power, $P_{B A T}$, according to (1) [47].

\subsection{Control policy and power profile smoothness evaluation}

The ESS is designed to balance the power demand with power generation as well as to store energy during high generation periods, which can be subsequently exploited to supply electricity during a period of high demand [8]. Therefore, the main goal of the energy management design is to control the power inverter-rectifier to concurrently preserve the battery SOC within secure limits and to "smooth" the power profile exchanged with the grid, i.e., minimizing the grid power fluctuations and grid power peaks. In this concern, a set of performance indicators is defined to evaluate, quantify, and compare the grid power profile achieved by an EMS strategy. Lower performance indicator values mean an improved energy management strategy. The performance indicators have been defined in $[32,49,47,42]$ and are recalled below for the complete understanding of the paper.

(1) Positive and negative grid power peaks:

$$
\begin{gathered}
P_{G, M A X}=\max \left(P_{G R I D}\right), \\
P_{G, M I N}=\min \left(P_{G R I D}\right),
\end{gathered}
$$

where $P_{G, M A X}$ and $P_{G, M I N}$ are the maximum power delivered by the grid and the maximum power fed into the grid in one year, respectively. 
(2) Maximum Power Derivative (MPD) is the maximum grid power profile ramp-rate (i.e., the slope in two consecutive samples, being the sampling period $T_{s}=900 \mathrm{~s}$ ) in the year under study. The $M P D$ indicator is expressed in $\mathrm{W} / \mathrm{h}$ and it is determined as follows:

$$
\begin{gathered}
M P D=\max \left(\left|P_{\text {GRID }}\right|\right), \\
P_{\text {GRID }}(n)=\left[P_{\text {GRID }}(n)-P_{\text {GRID }}(n-1)\right] / T_{s},
\end{gathered}
$$

where $\dot{P}_{\text {GRID }}$ is the grid power profile ramp-rate.

(3) Average Power Derivative ( $A P D$ ) is the annual average value, expressed in $\mathrm{W} / \mathrm{h}$, of the absolute value of the grid power profile ramp-rates. The APD indicator is expressed as follows:

$$
A P D=\frac{1}{N} \sum_{n=1}^{N}\left|P_{G R I D}(n)\right|
$$

being $N$ the number of samples in one year.

(4) Power Profile Variability ( $P P V$ ) measures the grid power profile steadiness. It is calculated as follows:

$$
P P V=\frac{\sqrt{\sum_{f=f_{i}}^{f_{f}} P_{G R I D, f}^{2}}}{P_{D C}},
$$

where $P_{\text {GRID, } f}$ is grid power harmonic at $f$ frequency, $f i$ and $f_{f}$ are the initial and final frequencies, respectively, and $P_{D C}$ is the yearly power average value. In addition, this indicator only evaluates frequencies above $f_{i}=1.65 \times 10^{-6} \mathrm{~Hz}$ (i.e., one week or less variation periods), since the energy management strategy seeks to compensate daily variations. Furthermore, the maximum frequency used to calculate $P P V$ is half of the sampling frequency $f_{f}=5.55 \times 10^{-4} \mathrm{~Hz}$ (i.e., Nyquist frequency) [47,42].

\section{FLC strategy}

\subsection{Control block-diagram}

The proposed FLC energy management strategy (EMS-FC) extends the fuzzy EMS-ERoC strategy presented in $[49,47]$ used to smooth the grid power profile of a residential grid-connected MG. The new design is inspired in [42] trying to improve its features and includes the MG power forecasting to predict the future MG behavior, so that, the power forecast error is used by the FLC to modify the grid power according to the battery SOC [48]. Conversely to previous design [47], the proposed fuzzy EMS-FC strategy uses a Central Moving Average (CMA) filter [54] to compute the MG net power average considering the MG net power of previous 12-hours and the forecast of the MG net power for the next 12-hours.

The proposed fuzzy EMS-FC block diagram is shown in Fig. 2 and includes the following blocks [48]: a CMA filter block used to compute the MG net power average, $P_{C T R}$; a 3-hours filter block used to reduce the high variability associated with the forecast error and to compute the average forecast error of the previous 3-hours, $P_{E}^{3 H}$; a LPF block used to compute the battery SOC average of the previous 24-hours, $S O C_{A V G}$; a battery block used to estimate the battery SOC according to the battery SOC estimator; and, a FLC block used to improve the grid power profile according to the battery SOC and the MG forecast error of the previous 3-hours. Forecast procedure and battery SOC estimator principle are given in Appendix A and B, respectively. 


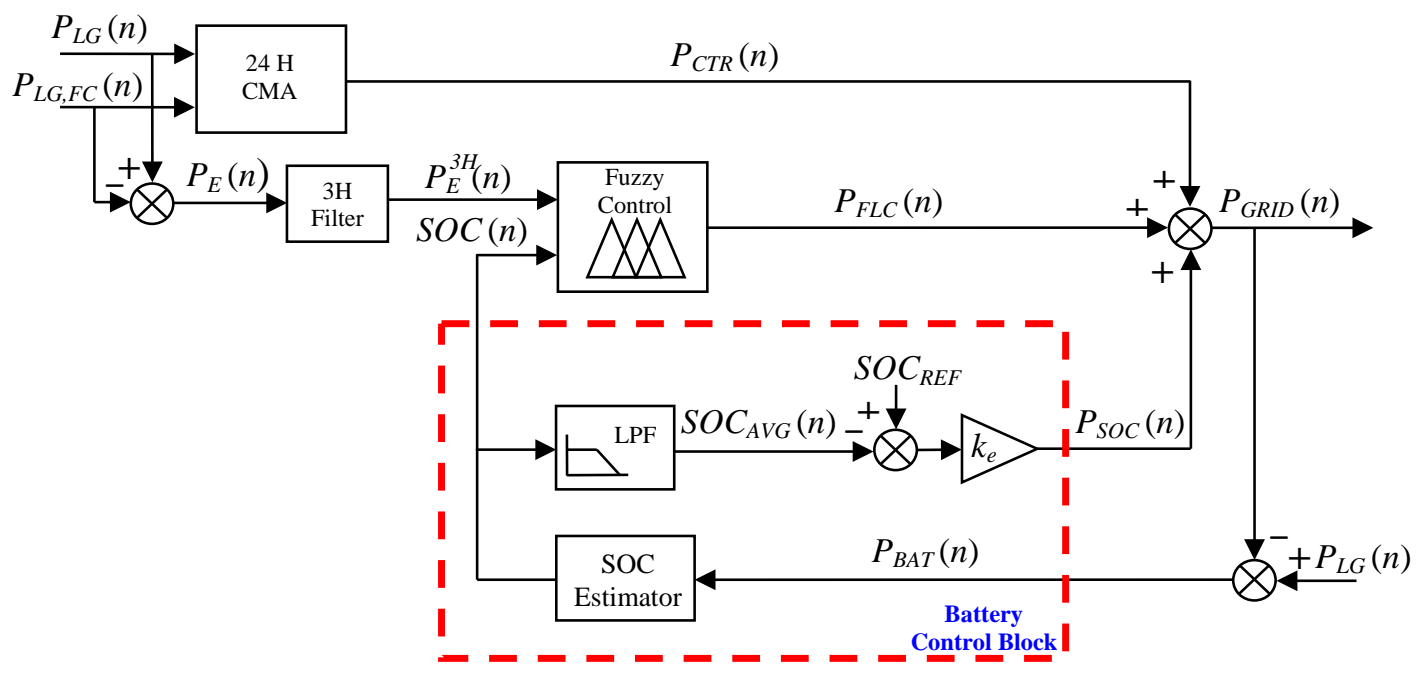

Fig. 2. Block diagram of the proposed EMS based on microgrid power forecasting $[48]^{1}$.

From Fig. 2, the grid power profile of the proposed fuzzy EMS-FC strategy is defined as the sum of three components [48], as follows:

$$
P_{G R I D}(n)=P_{C T R}(n)+P_{S O C}(n)+P_{F L C}(n)
$$

where $P_{C R T}$ is the CMA filter output, $P_{S O C}$ is the battery control loop output, and $P_{F L C}$ is the FLC output. Each component presented in (10) plays a particular role in the proposed energy management strategy as is described below.

The first component, $P_{C T R}$, is computed by means of a 24-hours CMA filter [54], which uses the MG net power of the previous 12-hours and the MG net power forecast for the next 12-hours to estimate the MG net power average [48]. Note that the use of the MG forecast of the following 12-hours allows the energy management strategy to work with the CMA filter instead of the SMA filter, which eliminates the lag introduced by filter action. In this regard, $P_{C T R}$ is computed as follows:

$$
\begin{gathered}
P_{C T R}(n)=\left[P_{L G}^{12 H}(n)+P_{L G, F C}^{12 H}(n)\right] / 2, \\
P_{L G}^{12 H}(n)=\frac{1}{M_{12}} \sum_{k=1}^{M_{12}} P_{L G}(n-k), \\
P_{L G, F C}^{12 H}(n)=\frac{1}{M_{12}} \sum_{k=1}^{M_{12}} P_{L G, F C}(n+k),
\end{gathered}
$$

where $P_{L G}^{12 H}$ is the MG net power average value of the previous 12-hours, $P_{L G, F C}^{12 H}$ is the MG net power forecast average value for the next 12-hours, $M_{12}$ is the number of samples in 12-hours, and $P_{L G, F C}$ is the MG net power forecast.

The second component, $P_{S O C}$, is used to keep the battery SOC center close to the $75 \%$ of the rated battery capacity $[42,48]$. This component is proportional to the error between the battery SOC reference value and the battery SOC average value of the previous 24-hours. $P_{S O C}$ is expressed as follows:

${ }^{1}$ C2016 IEEE, Reprinted, with permission, from Arcos-Aviles D, Guinjoan F, Marietta MP, Pascual J, Marroyo L, Sanchis P. Energy management strategy for a grid-tied residential microgrid based on Fuzzy Logic and power forecasting. IECON 2016 - 42nd Annu. Conf. IEEE Ind. Electron. Soc., Florence, Italy: IEEE; 2016, p. 4103-8 


$$
\begin{gathered}
P_{S O C}(n)=k_{e}\left[S O C_{R E F}-S O C_{A V G}(n)\right], \\
\operatorname{SOC}_{A V G}(n)=\frac{1}{M_{24}} \sum_{k=1}^{M_{24}} \operatorname{SOC}(n-k),
\end{gathered}
$$

where $S O C_{R E F}$ is the battery SOC reference value (i.e., $S O C_{R E F}=75 \%$ in this study), $S O C_{A V G}$ is the battery SOC average value of the previous 24-hours, $k_{e}$ is the proportional gain constant, which is set to $0.05 \mathrm{~kW} / \%$ in order to obtain a high enough phase margin in the battery SOC control loop [42].

Finally the third component, $P_{F L C}$, is used to improve the grid power profile according to the battery SOC and the MG power forecast error of the previous 3-hours [48]. This block is responsible for correcting the forecast error if needed, that is, it controls the grid power profile depending on whether the forecast error can be compensated by the ESS according to the battery SOC. This component is computed by a two-input, one-output, and 25 rules FLC that assumes a Mamdani-based inference and Center of Gravity defuzzification [37]. The FLC inputs are the current battery SOC and the power forecast error of the previous 3-hours $P_{E}^{3 H}$, which is calculated as follows:

$$
P_{E}^{3 H}(n)=\frac{1}{M_{3}} \sum_{k=1}^{M_{3}} P_{E}(n-k),
$$

where $M_{3}$ is the number of samples in the last 3-hours and $P_{E}$ is the MG power forecast error, which is defined as the difference between the measured MG net power, $P_{L G}$, and its expected value, $P_{L G, F C}$, as follows:

$$
P_{E}(n)=P_{L G}(n)-P_{L G, F C}(n) .
$$

\subsection{FLC design}

The design FLC methodology follows the works presented by the authors in [46-47]. Regarding the FLC design, the adjustment of fuzzy parameters (e.g., Membership Functions number, type, mapping, and rule-base) is performed by an off-line adjustment procedure presented in [46] with the purpose of minimizing the magnitude of the performance indicators defined in Section 2.2. This adjustment makes use of real data of renewable power generation and load power demand, shown in Fig. 3. These data have been obtained by measuring along one year the output power of both RES and the load consumption in the

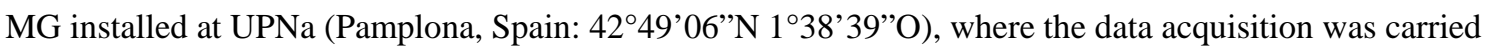
out by means of power analyzers recording data every 15 minutes (i.e., a sampling period of $T_{s}=900 \mathrm{~s}$ ). It can be pointed out that this one year measurement time used to the FLC training and final design mostly assures all the possible scenarios of RES production and load consumption for this type of residential systems. Moreover, these real data will be also used for performance comparison purposes in the next section.

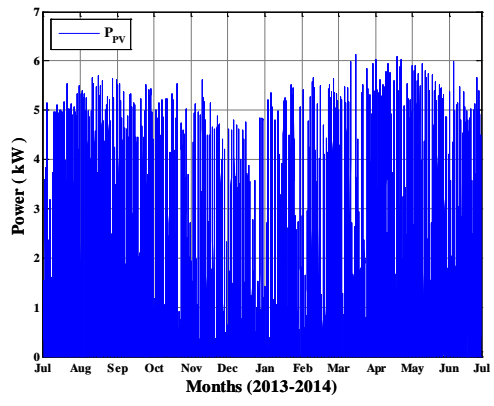

(a)

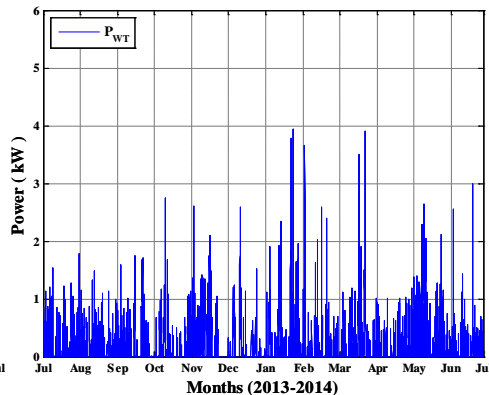

(b)

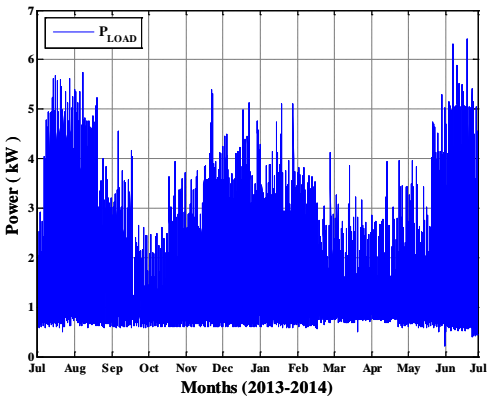

(c)

Fig. 3. Renewable power generation and load power demand measured at UPNA microgrid from July 2013 to July 2014 (a) photovoltaic power, (b) wind turbine power, and (c) load demand power. 
As a result, five triangular Membership Functions (MF) are defined for each input variable as shown in Fig. 4 [48]. These MFs correspond to five fuzzy subsets noted as NB, NS, ZE, PS and PB where B stands for "Big”, $\mathrm{S}$ for "Small”, $\mathrm{N}$ for "Negative”, $\mathrm{P}$ for "Positive” and ZE for "Zero". In addition, the MFs are distributed along the variation range of each input. The input SOC variation range has to satisfy the battery constraints defined in Appendix 1, whereas the input $P_{E}^{3 H}$ variation range is defined as follows:

$$
-P_{e} \leq P_{E}^{3 H}(n) \leq+P_{e},
$$

where $P_{e}$ is the maximum power forecast error allowable in the MG. The case under study assumes a maximum power forecast error of $6 \mathrm{~kW}$.

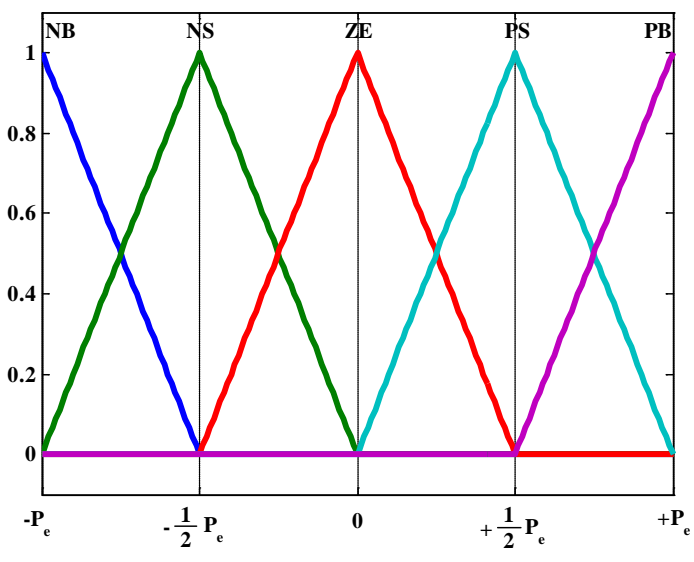

(a)

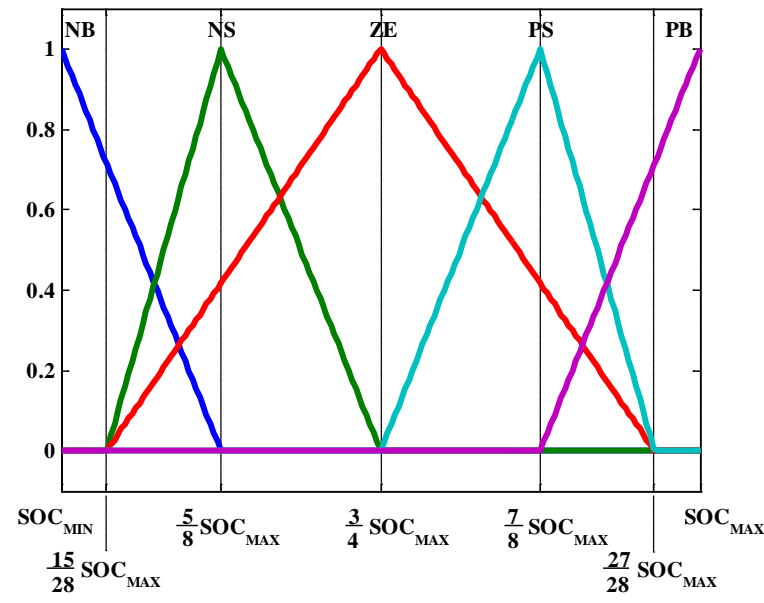

(b)

Fig. 4. MFs for the FLC input variables (a) power forecast error and (b) battery SOC [48] $]^{1}$.

Moreover, nine triangular MFs are defined for the controller output $P_{F L C}$. The MFs are shown in Fig. 12 [48] and are associated to nine fuzzy subsets noted as NB, NM, NS, NSS, ZE, PSS, PS, PM and PB, where besides B, S, N, P and ZE previously defined, M stands for "Medium" and SS for "Smallest". Similarly to the inputs MFs, the MFs for the FLC output are distributed along the variation range defined as follows:

$$
P_{N} \leq P_{F L C}(n) \leq P_{P},
$$

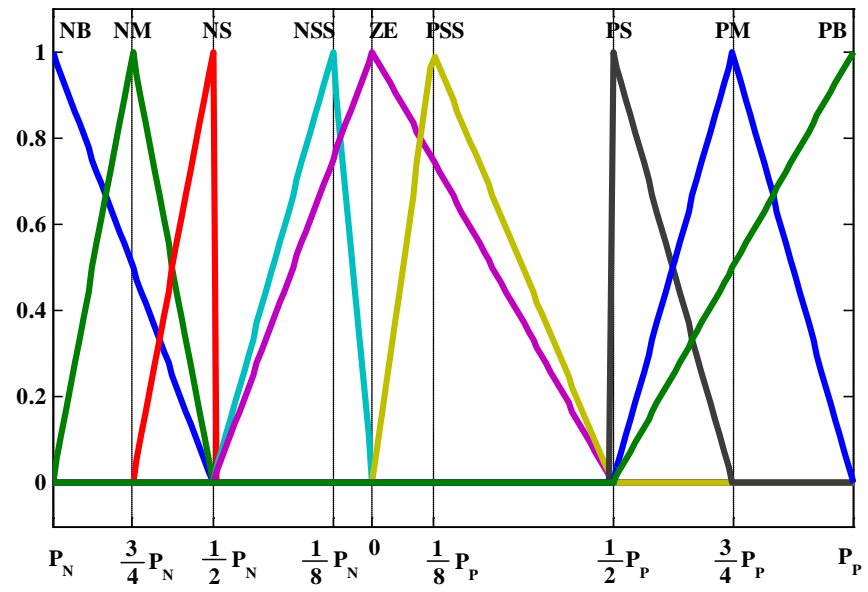

${ }^{1}$ (C)2016 IEEE, Reprinted, with permission, from Arcos-Aviles D, Guinjoan F, Marietta MP, Pascual J, Marroyo L, Sanchis P. Energy management strategy for a grid-tied residential microgrid based on Fuzzy Logic and power forecasting. IECON 2016 - 42nd Annu. Conf. IEEE Ind. Electron. Soc., Florence, Italy: IEEE; 2016, p. 4103-8 
Fig. 5. MFs for the FLC output $[48]^{1}$.

where $P_{N}$ and $P_{P}$ are the minimum and maximum power assigned to the controller output, respectively. From the adjustment procedure the variation range of the FLC output is set between $P_{N}=-0.3 \mathrm{~kW}$ and $P_{P}=0.45 \mathrm{~kW}[48]$.

Finally, the FLC rule-base is built considering the linguistic knowledge about the MG behavior. The rule-base presented in [48] is subjected to the adjustment procedure described in [46] to obtain a set of rules which concurrently minimizes the magnitude of the performance indicators defined in Section 2.2 and improves the grid power profile quality. After this procedure, the optimized fuzzy rule-base consists of 25-rules as presented in Table 1

Table 1

Optimized FLC rule-base (inputs SOC(n), and $\mathrm{P}_{\mathrm{E}}$, output $\mathrm{P}_{\mathrm{FLC}}$ )

\begin{tabular}{lllllll}
\hline \multirow{2}{*}{$\boldsymbol{P}_{\text {FLC }}(\boldsymbol{n})$} & \multicolumn{5}{c}{$\boldsymbol{P}_{E}^{3 H}(\boldsymbol{n})$} \\
\cline { 3 - 7 } & NB & NS & ZE & PS & PB \\
\hline \multirow{4}{*}{$\operatorname{SOC}(\boldsymbol{n})$} & NB & PB & PB & PSS & PS & PB \\
& NS & PM & NS & PSS & PS & PS \\
& PS & PSS & ZE & ZE & PSS & PM \\
& PS & NS & PM & NSS & NS & NSS \\
\hline
\end{tabular}

For instance, the first rule is formulated as: "IF the forecast error in the MG is Negative Big [i.e., the MG net power forecast is far greater than the measured value, $\left.P_{E}^{3 H}(n)<<0\right]$ AND the energy stored in the battery is Negative Big [i.e., the battery is highly discharged, SOC $(n)<<S O C_{R E F}$ ] THEN strongly increase the grid power (i.e., Positive Big) in order to charge the storage system [i.e. $P_{F L C}(n)>>0$ ]".

\section{Simulation results and comparison}

The simulation of the proposed EMS-FC strategy is performed using the historical data recorded from July 2013 to July 2014. In addition, the simulation results are compared with two previous strategies described in the literature [47,42]. The first one [47], hereinafter referred to as EMS \#1, is based on FLC approach without considering power forecast, whereas the second one [42], hereinafter referred to as EMS \#2, is not based on a FLC and considers both generation and demand forecasts.

Fig. 6 shows the grid power profile comparison for the three EMS strategies. As it can be seen, although the results achieved through the EMS \#1and EMS \#2 strategies are fairly acceptable, the proposed fuzzy EMS-FC strategy reduces the number and value of the negative power peaks in the grid power profile achieving a maximum power fed into the grid of $P_{G, M I N}=-1.487 \mathrm{~kW}$. Note that a negative sign of the grid power profile indicates a power absorbed by the mains. In addition, the proposed fuzzy EMS-FC strategy leads a reduction of the grid power fluctuations and power peaks, as shown in Fig. 6 (red dashed circles), the grid power peaks are reduced with respect to EMS \#1and EMS \#2 strategies.

\footnotetext{
${ }^{1}$ (C)2016 IEEE, Reprinted, with permission, from Arcos-Aviles D, Guinjoan F, Marietta MP, Pascual J, Marroyo L, Sanchis P. Energy management strategy for a grid-tied residential microgrid based on Fuzzy Logic and power forecasting. IECON 2016 - 42nd Annu. Conf. IEEE Ind. Electron. Soc., Florence, Italy: IEEE; 2016, p. 4103-8
} 

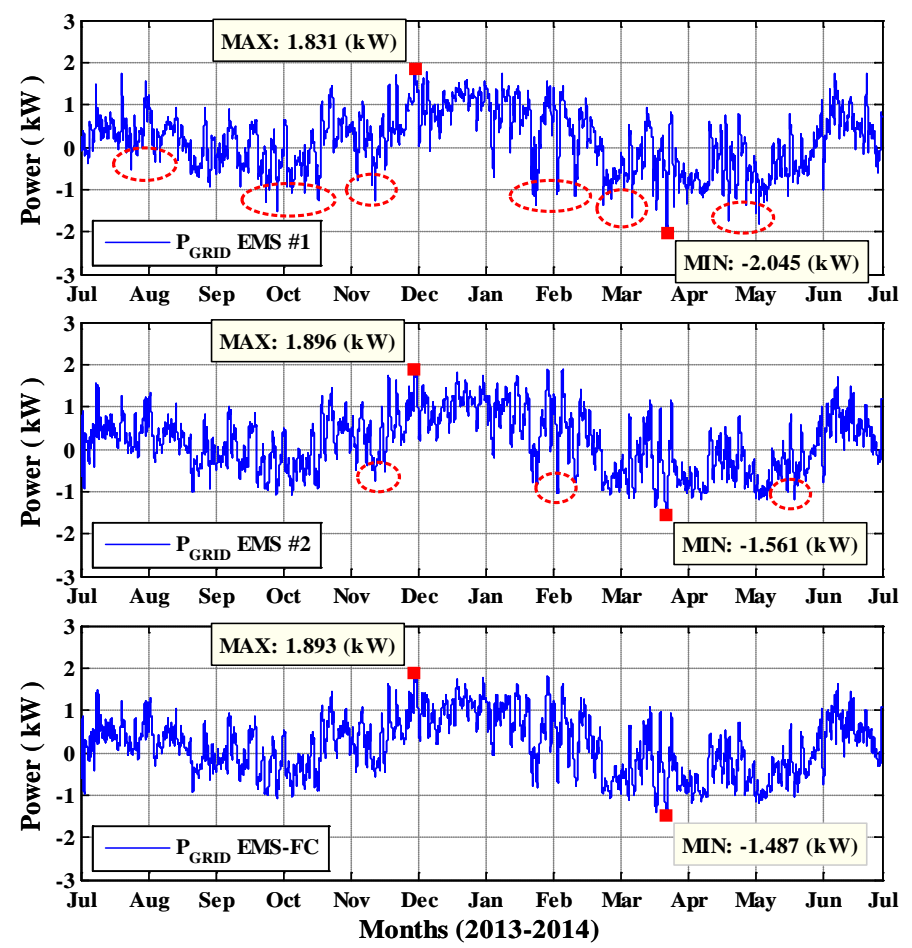

Fig. 6. Grid power profile comparison in the year under study. EMS \#1 (top), EMS \#2 (center), and proposed EMS-FC (bottom). Red dashed circles: negative fluctuations removed by the proposed EMS-FC

Moreover, Fig. 7(a) and Fig. 7(b) illustrate the battery SOC evolution and the SOC daily average profile, respectively, reached by the analyzed EMSs strategies during the year under study. The three strategies follow the same evolution pattern as shown in Fig. 7(a). However, the battery SOC evolution of the proposed fuzzy EMS-FC strategy is close centered to the $75 \%$ of the rated battery capacity (red solid line). This improvement can be further appreciated when analyzing the SOC daily average profile presented in Fig. 7(b) or when analyzing several consecutive days as shown in Fig. 10. The proposed fuzzy EMS-FC strategy achieves an average battery SOC of $73.85 \%$ in the year under study.
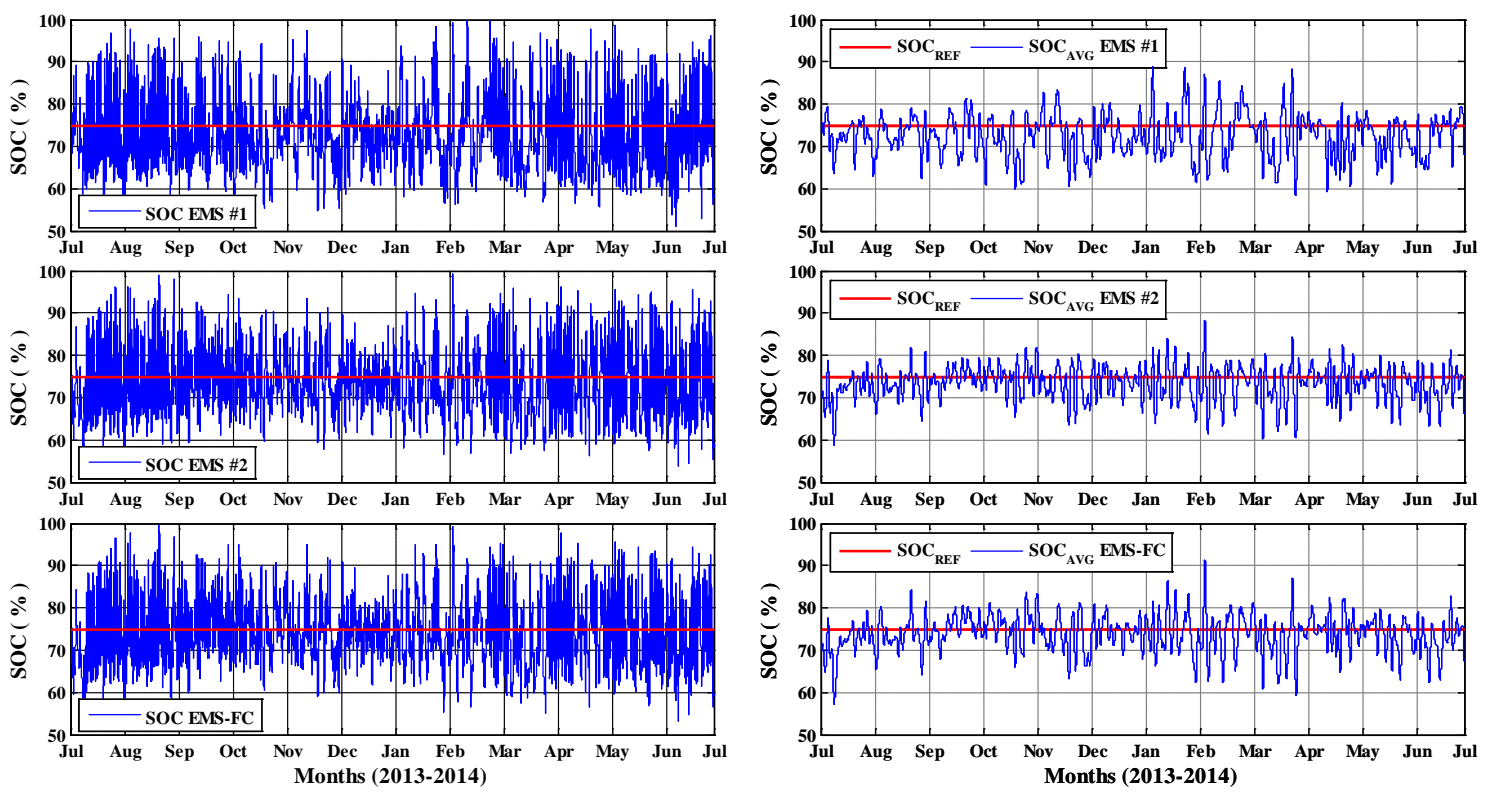

(a)

(b)

Fig. 7. Simulation results during the year under study (a) battery SOC and (b) daily average SOC. EMS \#1 (top), EMS \#2 (center), and the proposed EMS-FC (bottom). 
The improved behavior of the battery SOC evolution can also be evidenced in Fig. 8, which shows the histogram of the battery SOC. It can be seen that during $44.28 \%$ of the year under study, the battery SOC achieved by the proposed fuzzy EMS-FC strategy is maintained in a range between $70 \%-80 \%$ of the rated battery capacity. In contrast to the EMS \#1 strategy, the battery SOC is kept in this range during $37.04 \%$ of the year. In addition, the comparison with the EMS \#2 strategy shows a slight increase of $1.09 \%$ in the time period where the battery SOC is kept in this range, which leads to the ESS to be further prepared to compensate the fluctuations that may exist in the MG.

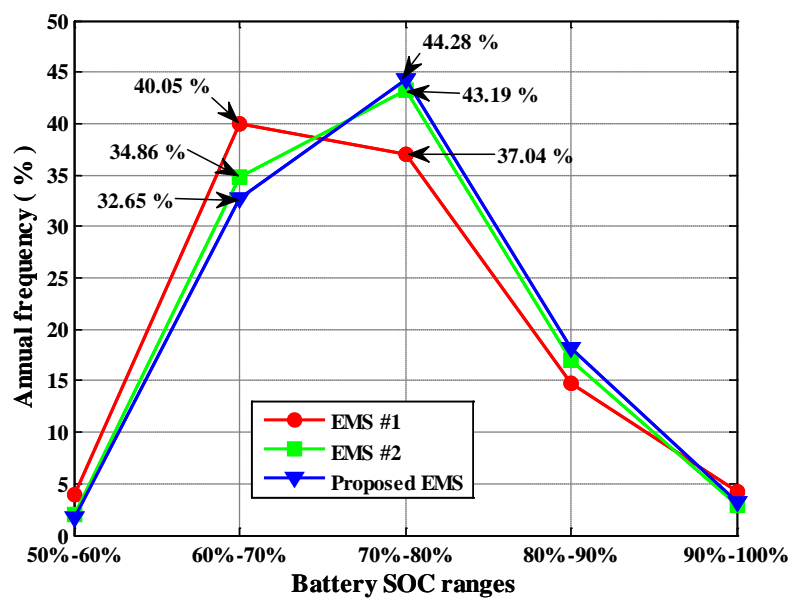

Fig. 8. Histrogram (in \%) of the battery SOC ranges established for the EMS \#1, EMS \#2, and the proposed EMS-FC strategy.

In addition, the controller ability to anticipate future events given the use of the forecast power is evidenced in Fig. 9, which compares the features between the EMS \#1 strategy and the proposed EMS-FC strategy along four consecutive days of the year under study.

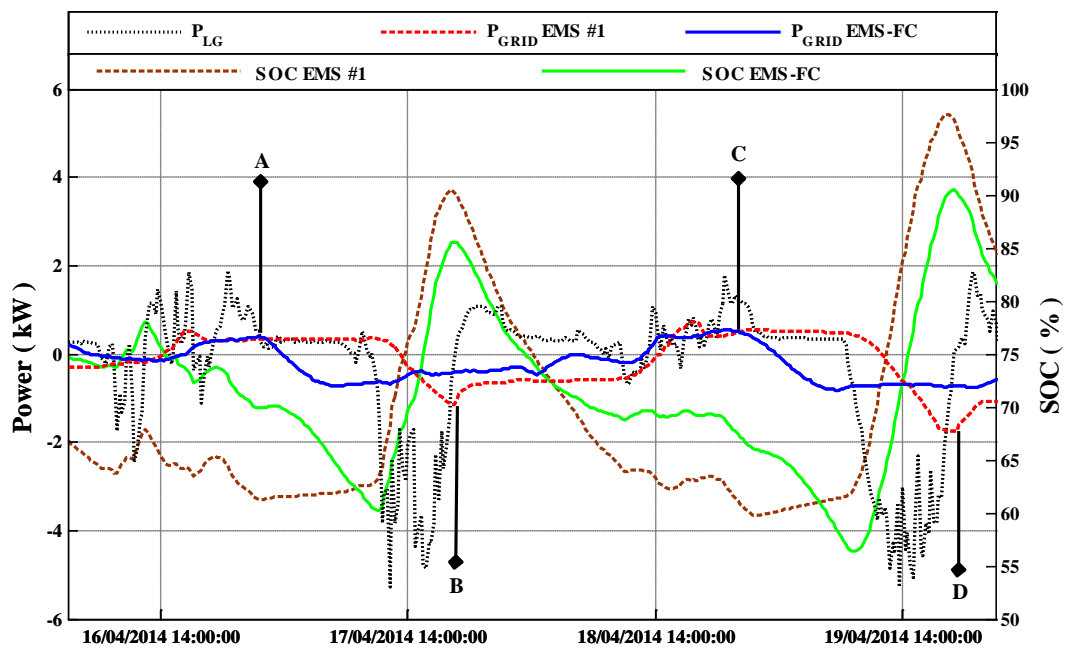

Fig. 9. Grid power profile and battery SOC comparison between the EMS \#1 and the proposed EMS-FC strategy.

As it can be seen at points A and C in Fig. 9, an increase in power generation is predicted for the next day in the MG (i.e., negative $P_{L G}$ profile on 17/04/2014 and 19/04/2017 close to 14:00, black dot line). Hence, the proposed fuzzy EMS-FC strategy decreases the grid power (blue solid line), which permits the battery discharge (green solid line) in order to prepare the ESS to absorb the future power generation. Conversely, the EMS \#1 where power forecast is not included, the grid power (red dashed line) is kept constant and rapidly falls as the power generation increases (i.e., negative $P_{L G}$ profile), which leads to both the battery charge over $90 \%$ of the rated battery capacity (brown dashed line) and a negative power peak in the grid power profile, as it can be seen at points B and D in Fig. 9.

Furthermore, Fig. 10(a) and Fig. 10(b) compare the grid power profile and the battery SOC evolution achieved by the analyzed EMSs strategies during two different periods of three consecutive days. The 
results highlight the advantages of the proposed fuzzy EMS-FC strategy with respect previous strategies $[47,42]$. The resulting grid power profile of the proposed EMS-FC strategy (blue solid line) shows minimum fluctuations and minimizes the positive and negative peaks with respect to the EMS\#1 (light blue dash-dot line) and EMS \#2 (red dashed line) strategies. Moreover, in Fig. 10 (bottom) evidences that the battery SOC reached by the proposed EMS-FC oscillates closer to the $75 \%$ of the battery rated capacity.

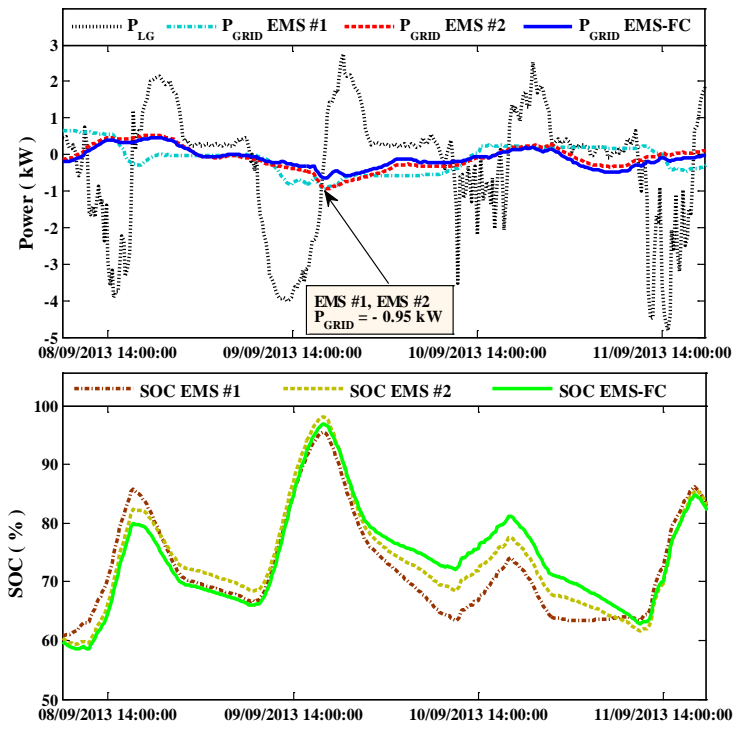

(a)

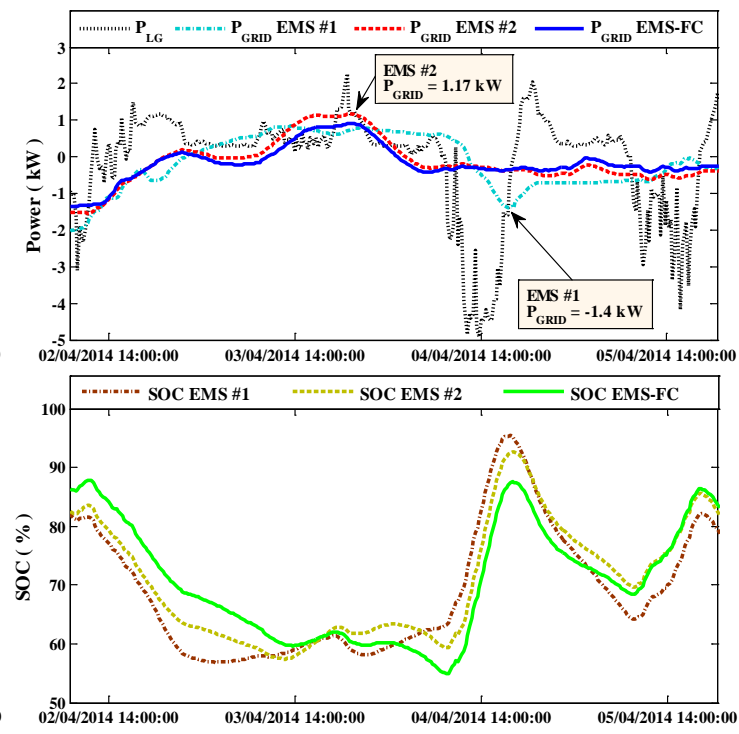

(b)

Fig. 10. Grid power profile and battery SOC comparison for the EMS \#1, EMS \# 2 and the proposed EMS-FC strategy.

Additionally, the enhanced behavior of the proposed fuzzy EMS-FC is verified by computing the performance indicators described in Section 2.2. The results are summarized in Table 2 Note that for comparison purposes the values of the performance indicators obtained for the case of a microgrid without an EMS (i.e., $P_{G R I D}=P_{L G}$ ) and a microgrid that uses the SMA strategy are presented in Table 2 .

Table 2

Performance indicators comparison for the EMS \#1, EMS \#2, and the proposed EMS-FC strategy

\begin{tabular}{|c|c|c|c|c|c|}
\hline Energy Management Strategy & $\begin{array}{c}P_{G, M A X} \\
(\mathbf{k W})\end{array}$ & $\begin{array}{c}P_{G, M I N} \\
(\mathbf{k W})\end{array}$ & $\begin{array}{l}M P D \\
(\mathrm{~W} / \mathrm{h})\end{array}$ & $\begin{array}{c}A P D \\
(\mathrm{~W} / \mathrm{h})\end{array}$ & $P P V$ \\
\hline MG net power & 5.75 & -6.45 & 18468 & 1121 & 13.3 \\
\hline SMA strategy & 4.71 & -2.40 & 12839 & 44.42 & 2.51 \\
\hline EMS \#1 [47] & 1.83 & -2.04 & 817 & 56.15 & 2.79 \\
\hline EMS \#2 [42] & 1.90 & -1.56 & 619 & 52.65 & 2.98 \\
\hline Proposed EMS-FC & 1.89 & -1.48 & 480 & 51.79 & 2.76 \\
\hline
\end{tabular}

The proposed EMS-FC strategy achieves an important reduction in the magnitude of the defined performance indicators with respect to previous strategies [47,42]. In short with respect to EMS \#1 strategy, the maximum power fed into the grid $P_{G, M I N}, M P D, A P D$, and $P P V$ indicators have been reduced in $27.4 \%, 41.2 \%, 7.8 \%$, and $1.1 \%$, respectively. Note that given the widespread reduction of $P_{G, M I N}$ and $M P D$ indicators, the slight increase of the maximum power delivered by the grid $P_{G, M A X}$, can be considered negligible (i.e., an increment of only $70 \mathrm{~W}$ in the maximum grid power peak for the year under study). In addition, with respect to EMS \#2 strategy, $P_{G, M A X}, P_{G, M I N}, M P D, A P D$, and $P P V$ indicators have been reduced in $0.52 \%, 5.13 \%, 22.5 \%, 1.6 \%$, and $7.4 \%$, respectively, which confirms the low variability of the grid power profile achieved with the proposed fuzzy EMS-FC.

Finally, Fig. 11 shows the grid power ramp-rates along the year under study achieved by the analyzed EMSs strategies. As it can be seen in Fig. 11(a) and Fig. 11(b), the proposed fuzzy EMS-FC strategy 
reduces the ramp-rates with respect to EMS \#1 and EMS \#2 strategies. This result confirms the reduction of $M P D$ indicator reaching a maximum value of $480.5 \mathrm{~W} / \mathrm{h}$ in the year under study, as shown in Fig. 11(c). Note that the grid power ramp-rates reduction leads to a better quality in the power profile exchanged with the grid.

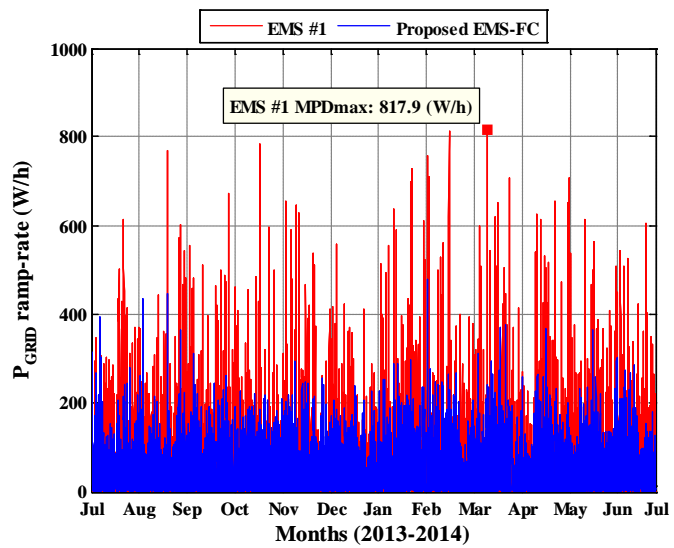

(a)

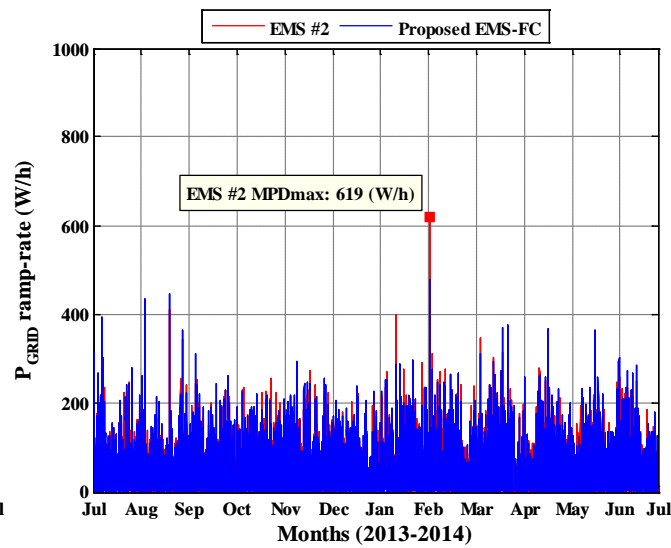

(b)

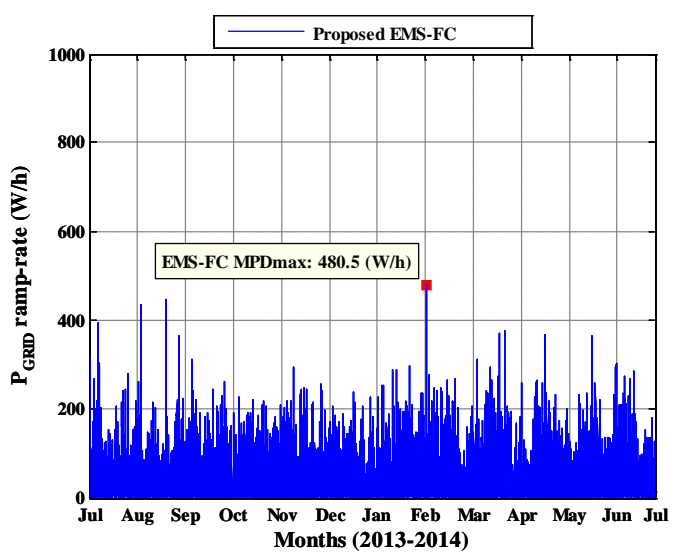

(c)

Fig. 11. Grid power ramp-rate comparison between (a) the EMS \#1 (red) and the proposed Fuzzy EMS-FC (blue); and, (b) the EMS \#2 (red) and the proposed Fuzzy EMS-FC (blue). (c) Grid power ramp-rates for the proposed Fuzzy EMS-FC.

\section{Experimental validation}

The experimental validation of the proposed fuzzy EMS-FC strategy is performed in the real MG installed at UPNa [32,47,42]. The microgrid is shown in Fig. 12 and includes a renewable generation system, a programmable load, a storage system, a power converter, a weather station and, a supervisory and control station. 


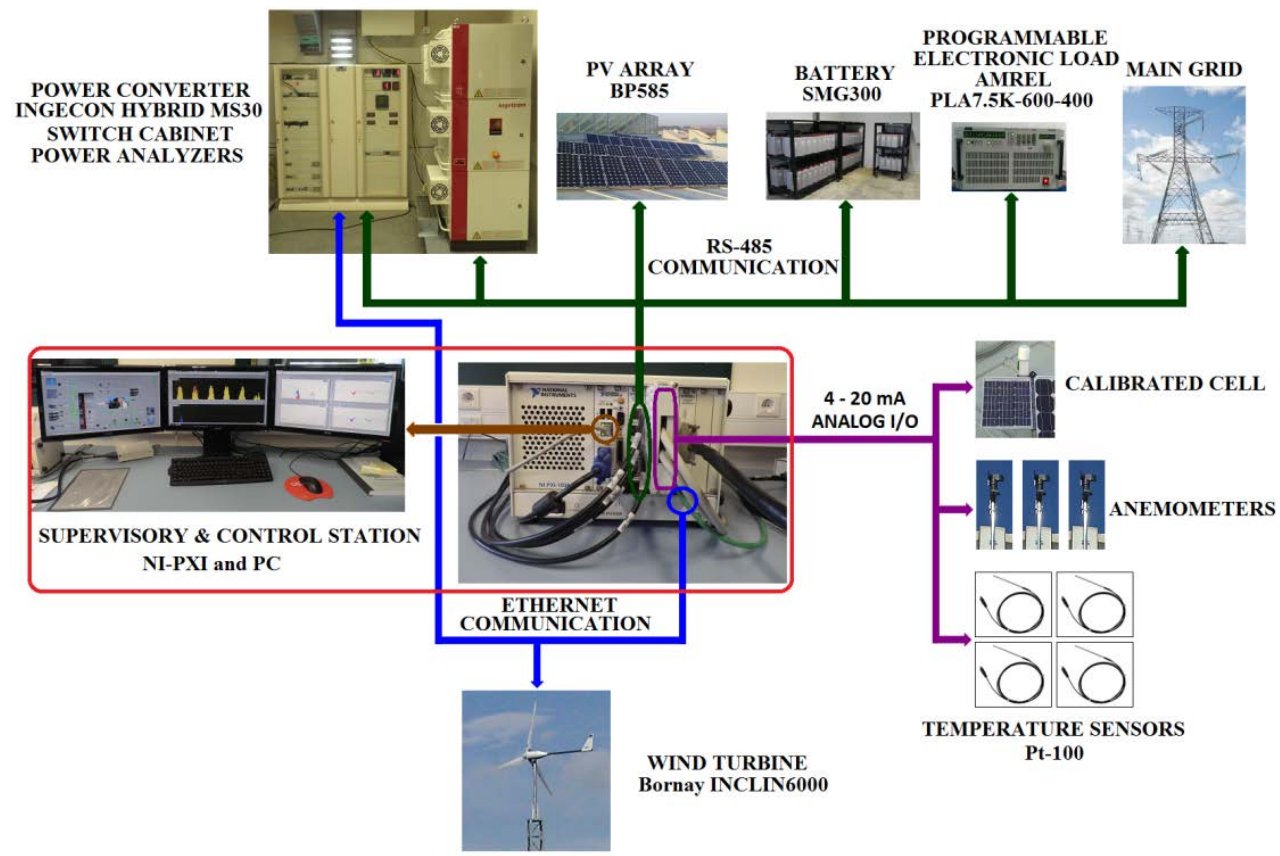

Fig. 12. UPNa microgrid. Configuration, components description and bus connections $[47]^{2}$.

\subsection{UPNa microgrid components}

The microgrid components have been described in $[47]^{2}$ and are recalled as follows:

The HRES consists of a PV and WT generators. The PV generator has a rated power of $4080 \mathrm{~W}$. It is composed of 48 BP585 solar panels [55] connected in four strings of 12 panels each, which are mounted south-facing with a tilt angle of $30^{\circ}$. The WT generator consist of a small WT Bornay INCLIN6000 [56] with a rated power of $6 \mathrm{~kW}$ installed at $20 \mathrm{~m}$ height over the ground next to the UPNa Renewable Energy Laboratory.

The programmable load consists of an AMREL PLA7.5K-600-400 electronic load, which is responsible for physically emulating the MG load power profile.

The battery ESS includes 120 FIAMM SMG300 stationary lead-acid cells connected in series. Each cell has a rated voltage of $2 \mathrm{~V}$ and a $\mathrm{C}_{10}$ capacity of $300 \mathrm{Ah}$ resulting in a total capacity of $72 \mathrm{kWh}$.

The UPNa microgrid uses a modified INGECON® HYBRID INVERTER, which comprises a WT power converter; a battery charger and PV power converter; and, an inverter module.

The microgrid weather station comprises: an irradiance calibrated cell, three anemometers distributed at the WT and PV generators, and four Pt-100 temperature sensors located at PV panel, battery, battery room, and outdoor.

Finally, the supervisory and control station includes National Instruments PCI eXtensions for Instrumentation (NI-PXI), power analyzers, and a general purpose PC. The NI-PXI uses four modules (i.e., NI PXI-8102 Embedded Controller, NI PXI-8433/4 Serial Interface, NI PXI-8231 Gigabit Ethernet Interface, and NI PXI-6238 Analog I/O data acquisition board) to acquire data from the power analyzers of each element belonging to the MG and to control them in real-time (i.e. sampling time of $1 \mathrm{sec}$.). The general purpose PC is used as the microgrid user interface, to check and update the data provided by Meteogalicia THREDDS Server [57], and to display the historic data of acquired variables by the NI-PXI.

\footnotetext{
${ }^{2}$ C2016 IEEE, Reprinted, with permission, from D. Arcos-Aviles; J. Pascual; L. Marroyo; P. Sanchis; F. Guinjoan, "Fuzzy Logic-Based Energy Management System Design for Residential Grid-Connected Microgrids," in IEEE Transactions on Smart Grid , vol. PP, no.99, pp.1-1
} 


\subsection{Experimental results and analysis}

The proposed fuzzy EMS-FC is programmed and compiled through LabVIEW platform, and subsequently is sent to the NI-PXI where the energy management strategy runs in real-time (i.e., the data acquisition time of each variable is set to one second). The proposed strategy is experimentally tested from Sep. 1st to Oct. 25th, 2015. The experimental results for different months are shown from Fig. 13 to Fig. 16.

Fig. 13 illustrates the measured and forecasted data from Sep. 8th to Sep. 14th, 2015 obtained at UPNa microgrid. For the case of the PV generator, the first days an acceptable forecast power is achieved, although, as shown in Fig. 13(a), high forecast error is noticeable the last day. For the WT generator, the forecast error is higher than the one obtained for the PV generator, as shown in Fig. 13(b). Conversely, the load forecast power achieved through the persistence forecast model is quite good with a low forecast error as shown in Fig. 13(c). Given the characteristics of generation and demand forecasts, the MG net power forecast is quite similar to the measured value, except to Sep. 13th which presents a higher forecast error as shown in Fig. 13(d). Here is when the proposed EMS acts to minimize the negative effects on the battery SOC caused by the unavoidable forecast errors. As shown in Fig. 14 (e.g., Sep. 13th), the grid power increases (red solid line) to help the ESS ( $P_{b a t}$ mustard-colored dashed line) for supplying the required load power (black dot line).

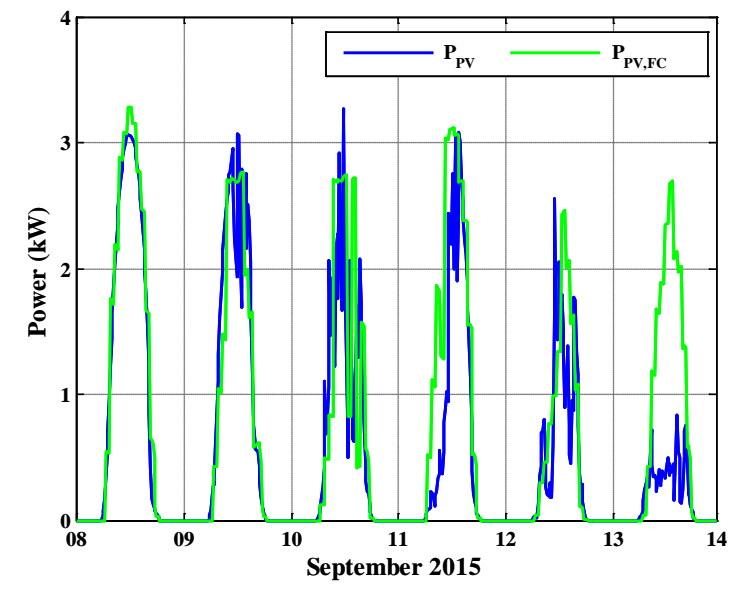

(a)

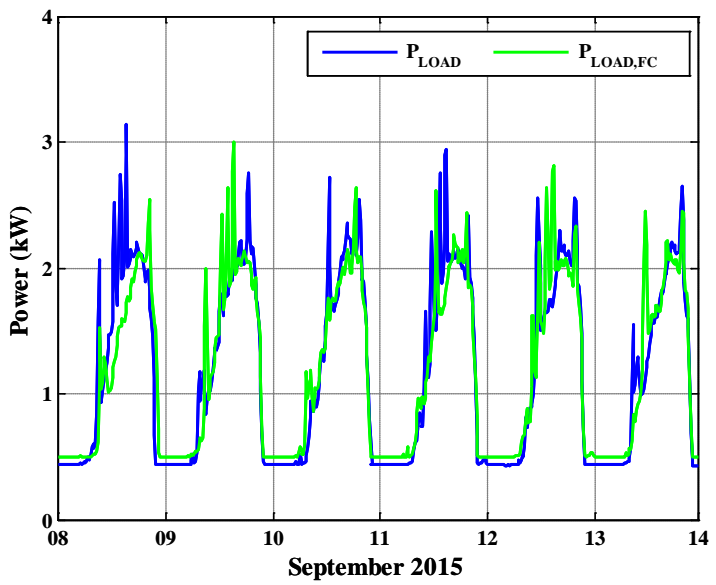

(c)

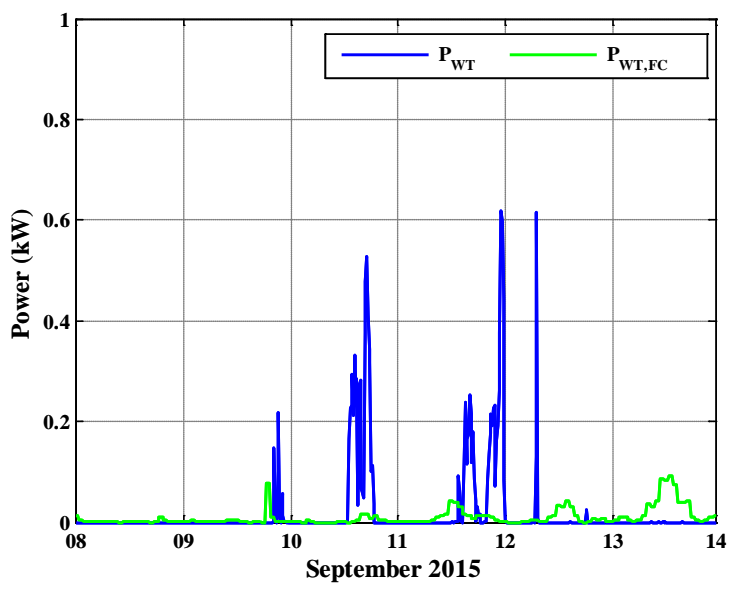

(b)

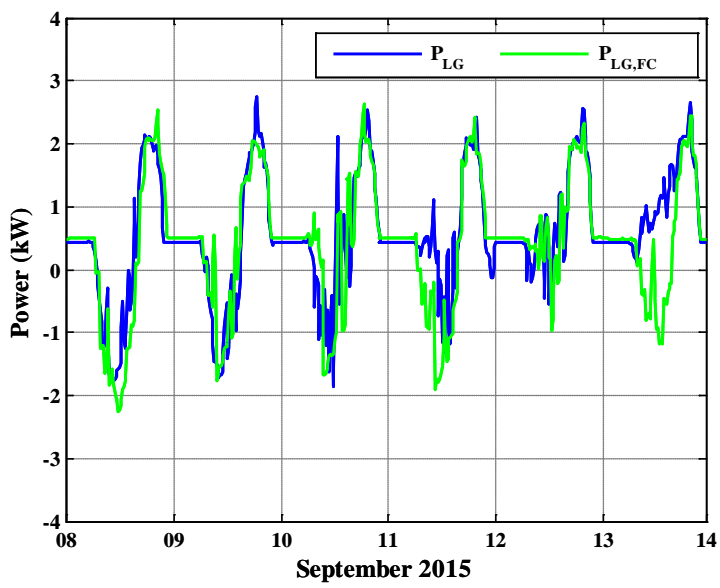

(d)

Fig. 13. Forecasted and measured data obtained at UPNa MG from Sep. $08^{\text {th }}-14^{\text {th }}, 2015$ (a) PV power, (b) WT power, (c) load power demand, and (d) MG net power. 


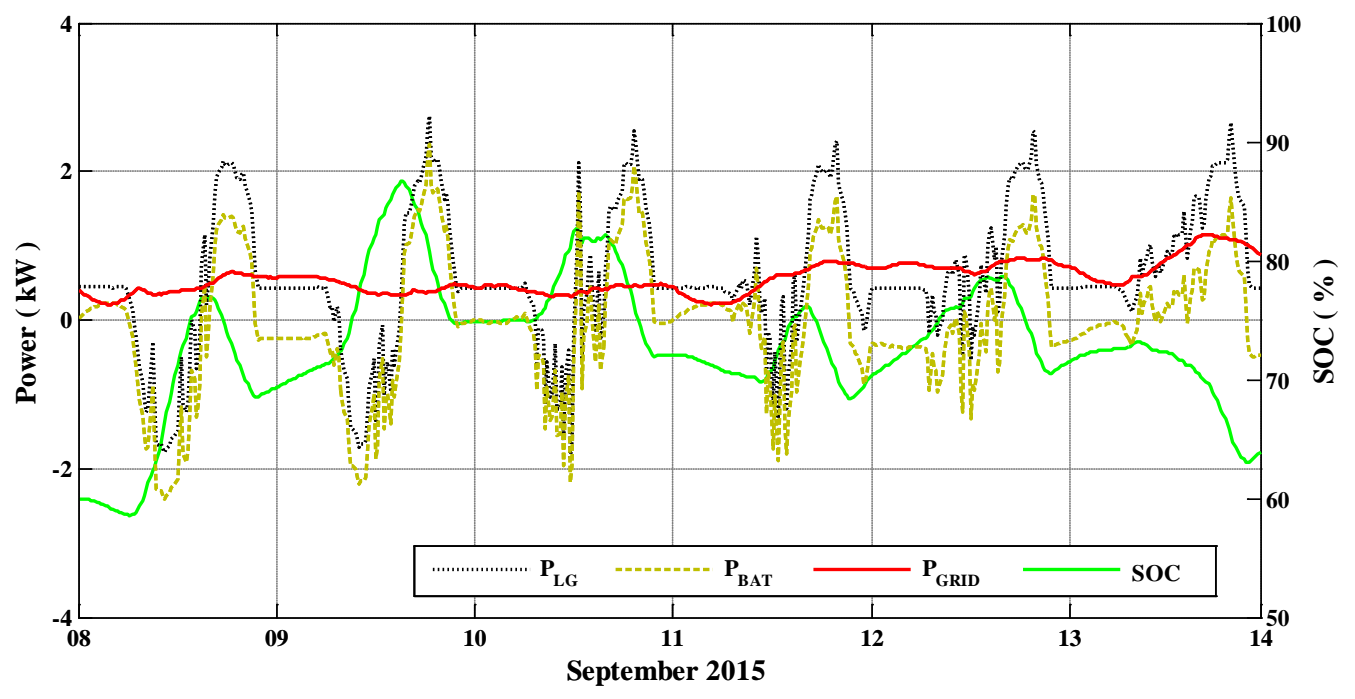

Fig. 14. Experimental results from Sep. $08^{\text {th }}-14^{\text {th }}, 2015$ achieved by the proposed fuzzy EMS-FC strategy.

Similarly, Fig. 15 illustrates the forecasted and measured data acquired from Oct. 10th to Oct. 25th, 2015 at UPNa microgrid. As it can be seen, the proposed fuzzy EMS-FC shows the same improved behavior than the one presented in September. In short, despite the forecast error of the PV and WT generators, shown in Fig. 15(a) and Fig. 15(b), respectively, and the load, Fig. 15(c), the proposed strategy smooths the gird power exchanged with the grid, as shown in Fig. 15(d).

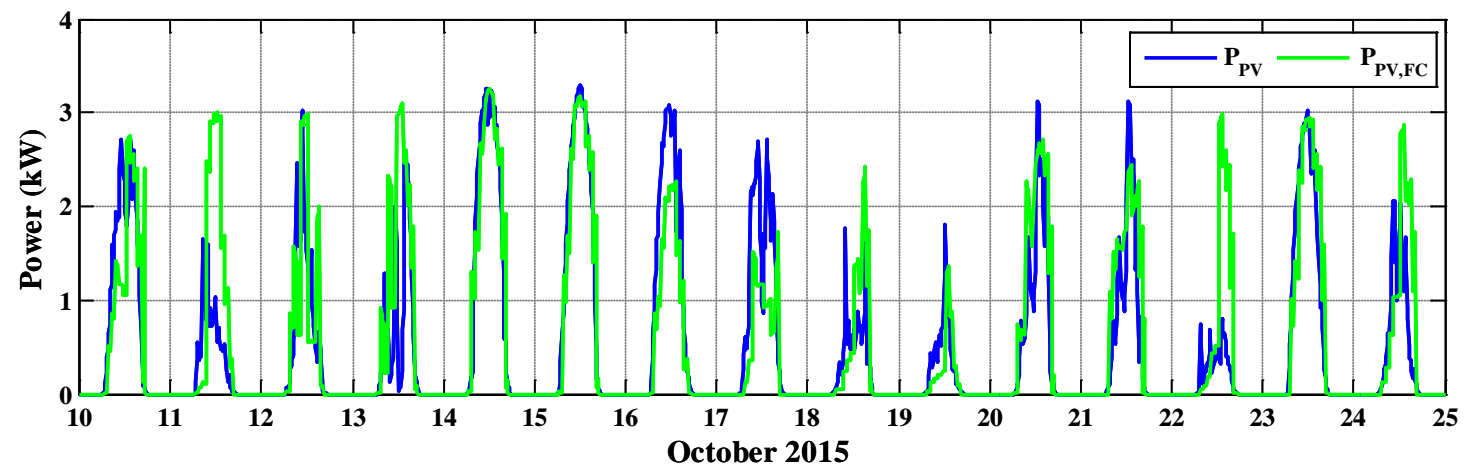

(a)

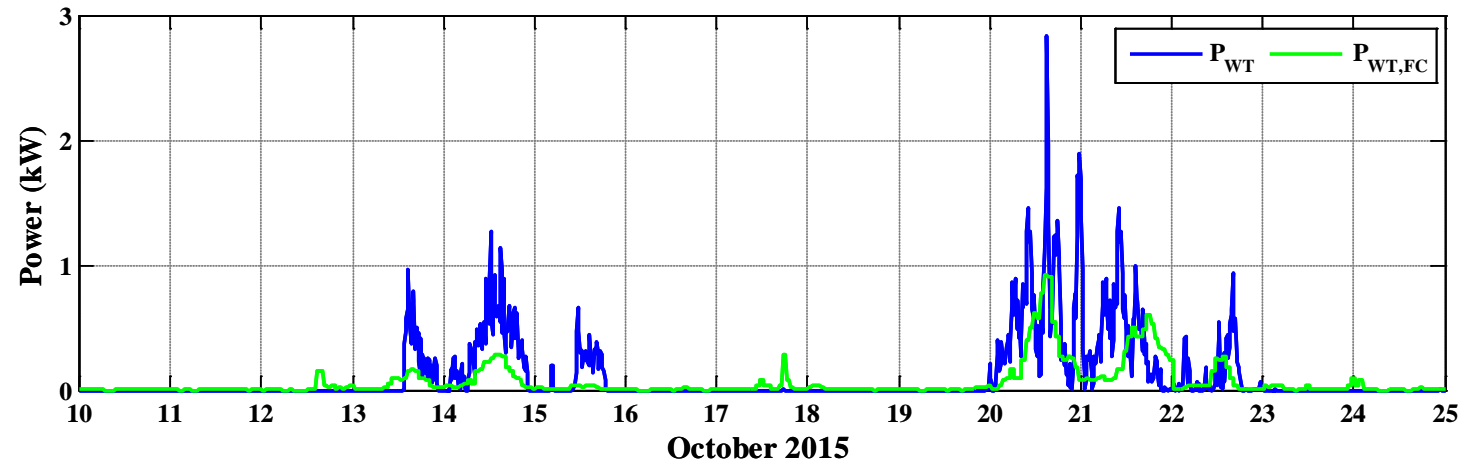

(b) 


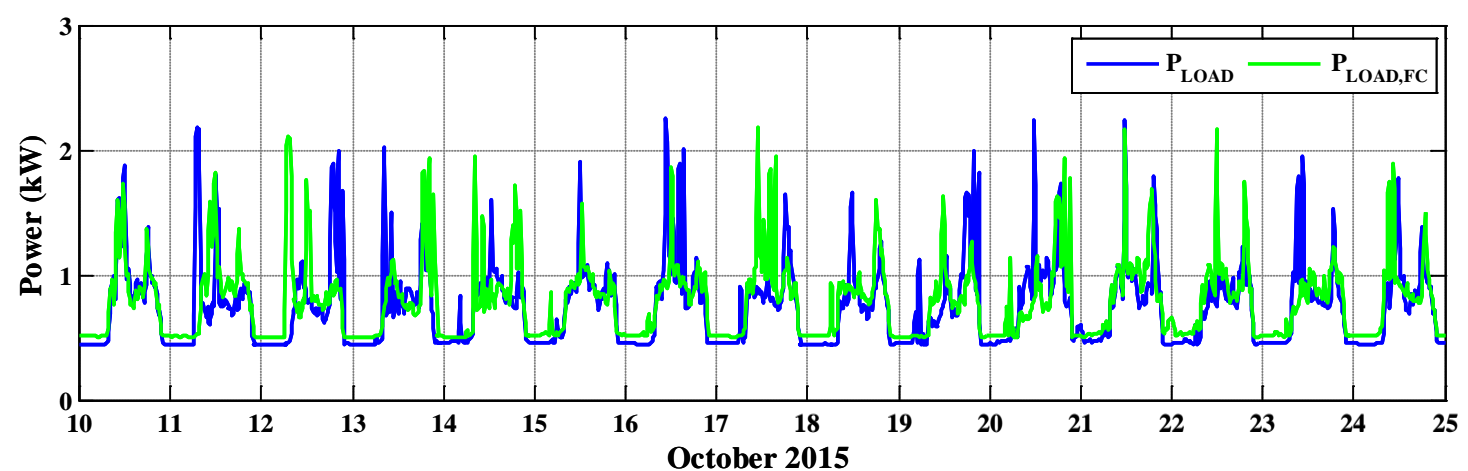

(c)

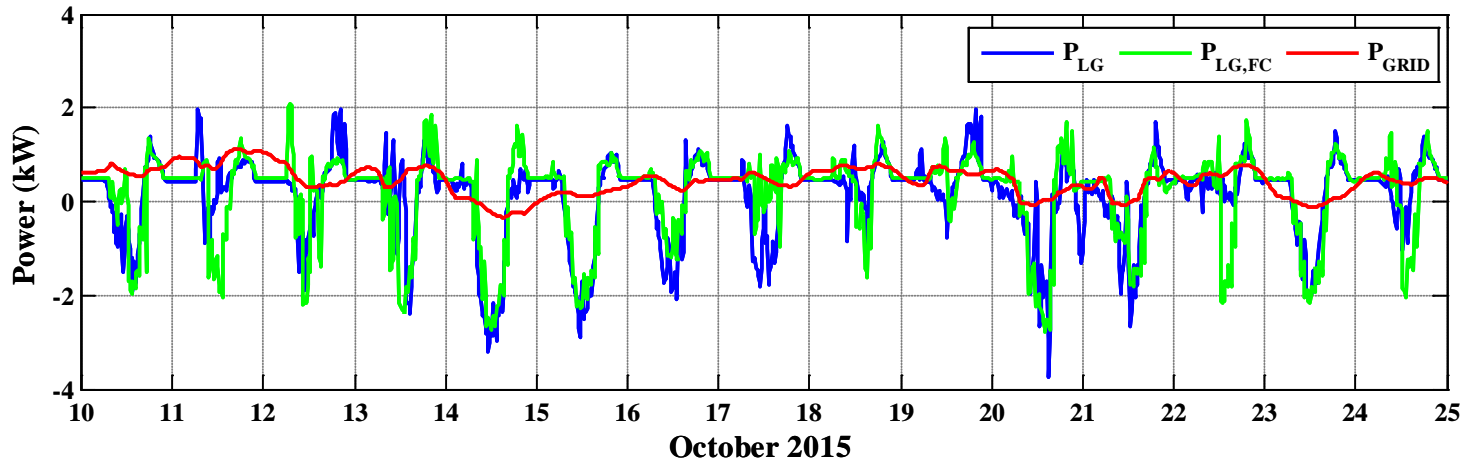

(d)

Fig. 15. Forecasted and measured data obtained at UPNa MG from Oct. $10^{\text {th }}$ to Oct. $25^{\text {th }}, 2015$ (a) PV power, (b) WT power, (c) load power demand, and (d) MG net power and resulting grid power profile.

Finally, Fig. 16 shows the grid power profile (red solid line), the battery SOC (green solid line), and the battery power (mustard-colored dashed line) achieved by the proposed fuzzy EMS-FC strategy. As it can be seen, the MG net power fluctuations (black dot line) are minimized while the battery SOC is kept between secure limits as expected from simulation results.

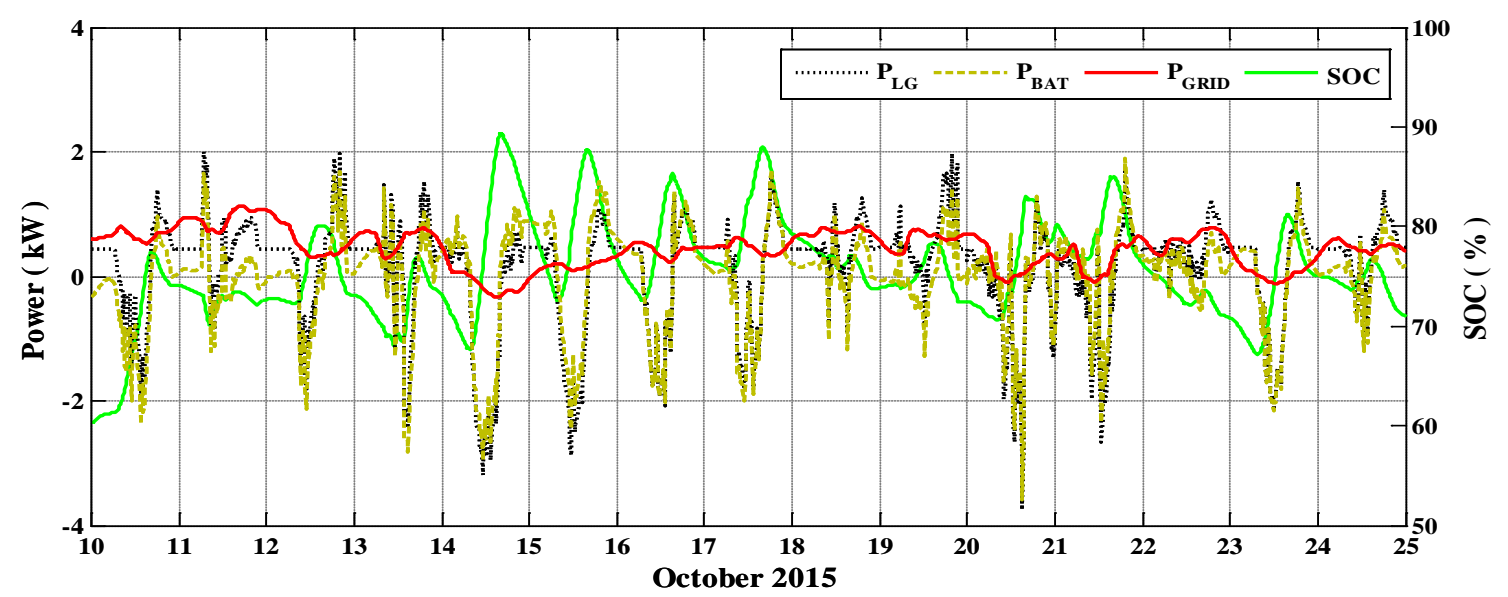

Fig. 16. Experimental results from Oct. $10^{\text {th }}$ to Oct. $25^{\text {th }}, 2015$ achieved by the proposed fuzzy EMS-FC strategy.

\section{Conclusions}

A low-complexity FLC-based EMS design has been presented for grid-connected residential systems including RES and a battery bank ESS where only the battery charger/grid-connected inverter is controllable. The design has been oriented to concurrently achieve a grid power profile smoothing and a controlled SOC excursion of the ESS between secure limits satisfying the load demand at any time. This approach has been followed since it can meet grid operator requirements to allow the penetration of RES in grid-connected systems and therefore to reduce the energy demand coming from the grid. 
The EMS design has been based on splitting the grid power profile as the sum of three components. The first component is computed by means of a CMA filter to fix a low-frequency grid power profile whereas the second one has been used to keep the battery SOC close to the $75 \%$ of its rated capacity. The third component is computed by a low complexity FLC of only 25 rules using generation and demand forecasting to reduce the negative impact of the forecast error on the grid power profile. Simulation results with previous approaches seeking the same objective have revealed the improvements reached by the proposed approach, particularly in terms of the maximum grid power derivative. Finally, the experimental validation results of the proposed fuzzy EMS-FC strategy carried out in a real residential microgrid implemented at UPNa has confirmed the robustness and the effectiveness of the fuzzy EMS-FC design.

\section{Acknowledgments}

This work is part of the project 2016-PIC-044 from the Universidad de las Fuerzas Armadas ESPE. The authors would like to acknowledge Gabriela Haro for her assistance in reviewing the technical English of this paper. This work was partially supported by the Spanish State Research Agency (AEI) and FEDER-UE under grants: DPI2015-67292, DPI2013-41224-P, DPI2013-42853-R and DPI2016-80641-R

\section{Appendix A. MG power forecasting}

Renewable generation forecast: $P_{G E N, F C}(n)$

The power generation forecast is estimated by Numerical Weather Prediction (NWP) [58,59] using the data provided by Meteogalicia THREDDS Server [57], which comprise a set of weather data (e.g., ambient temperature, wind speed at 10 meters of height above the ground, horizontal irradiance, atmospheric pressure) acquired through the Weather Research and Forecasting (WRF) model for the Iberian Peninsula. This model is updated every 12-hours with three days prediction horizon [48]. The power generation forecast, $P_{G E N, F C}$, is expressed as follows:

$$
P_{G E N, F C}(n)=P_{P V, F C}(n)+P_{W T, F C}(n),
$$

where $P_{P V, F C}$ and $P_{W T, F C}$ are the PV and WT power forecast, respectively, which are evaluated according to the following models:

\section{Photovoltaic model}

The PV module power output depends on different factors (e.g., material, temperature, incident irradiance...), and can be expressed as follows $[48,60,61]$ :

$$
P_{P V}=P_{S T C} \frac{G(\beta, \alpha)}{G_{S T C}}\left[1+\gamma\left(T_{C}-T_{\text {STC }}\right)\right] \text {, }
$$

where $P_{\text {STC }}$ is the PV module output power (W) under Standard Test Conditions (STC), $G(\beta, \alpha)$ is the incident irradiance on the plane of the panels $\left(\mathrm{W} / \mathrm{m}^{2}\right), G_{\text {STC }}$ is incident irradiance under STC $\left(\mathrm{W} / \mathrm{m}^{2}\right), \gamma$ is the power temperature coefficient, $T_{\text {STC }}$ is the temperature under STC $\left({ }^{\circ} \mathrm{C}\right)$, and $T_{C}$ is the cell temperature $\left({ }^{\circ} \mathrm{C}\right)$, which can be expressed as follows $[48,61]$ :

$$
T_{C}=\left(T_{a}-273\right)+\frac{G(\beta, \alpha)}{800} \cdot(N O C T-20),
$$

where $T_{a}$ is the ambient temperature (K) and $N O C T$ is the Nominal Operating Cell Temperature $\left({ }^{\circ} \mathrm{C}\right)$.

Note that $P_{S T C}, \gamma$, and NOCT values are provided by the PV panel manufacturer [55]. Conversely, the solar irradiance on a tilted plane, $G(\beta, \alpha)$, is estimated by means of the procedure described in [62] using the solar irradiance on a horizontal plane, $G_{0}$, which is provided by the local observatories. 


\section{Wind turbine model}

The wind turbine power can be estimated as follows [48,63,64]:

$$
P_{W T}=\frac{1}{2} \cdot \rho \cdot A \cdot C_{P} \cdot v_{(Z)}^{3},
$$

where $P_{W T}$ is the WT output power, $\rho$ is the air density $\left(\mathrm{kg} / \mathrm{m}^{3}\right), v_{(Z)}$ is the wind speed at the wind turbine hub-height $(\mathrm{m} / \mathrm{s}), A$ is the rotor swept area $\left(\mathrm{m}^{2}\right)$, and $C_{P}$ is the WT power coefficient. Note that $A$ and $C_{P}$ values are provided by the WT manufacturer [56]. In contrast, the air density should be estimated, since environmental conditions (e.g. temperature, atmospheric pressure...) can affect it. The air density is estimated as follows $[48,65]$ :

$$
\rho=\frac{M \cdot p}{T_{a} \cdot R}
$$

where $M$ is the air molar mass in $\mathrm{kg} / \mathrm{mol}, p$ is the atmospheric pressure $\left(\mathrm{N} / \mathrm{m}^{2}\right)$, and $R$ is the universal gas constant $[\mathrm{J} /(\mathrm{K} \cdot \mathrm{mol})]$.

Moreover, the local observatories usually measure the wind speed at 10 meters above the ground. Consequently, the WT power estimation requires the extrapolation of the wind speed provided by the local observatories to the wind speed at the WT hub-height. This extrapolation is computed as follows $[48,65,66]$ :

$$
v_{(Z)}=v_{\left(Z_{R E F}\right)} \cdot \frac{\ln \left(Z / Z_{0}\right)}{\ln \left(Z_{R E F} / Z_{0}\right)},
$$

where $V_{\left(Z_{R E F}\right)}$ is the wind speed at $Z_{R E F}$ height, $Z_{R E F}$ is the height of the measured data, $Z$ is the turbine hub-height, and $Z_{0}$ is the terrain roughness index.

Load forecast: $P_{L O A D, F C}(n)$

Conversely, the future load demand is estimated through the persistence forecast model assuming that the daily consumption is similar from one day to the next one. The persistence model uses the past data as the forecast for the next time period $[50,67]$. Thus, the load profile for the next day will be the same as the previous day, as follows:

$$
P_{L O A D, F C}\left(n+M_{24}\right)=P_{L O A D}(n)
$$

being $P_{L O A D, F C}$ the load demand forecast and $M_{24}$ the number of samples in the previous 24-hours. Note that the difference in load power demand between weekdays, weekends, and holidays is not considered in this study.

Net power forecast: $P_{L G, F C}(n)$

Finally, according to (2) the MG net power forecast, $P_{L G, F C}$, is computed as follows:

$$
P_{L G, F C}(n)=P_{L O A D, F C}(n)-P_{G E N, F C}(n) .
$$

\section{Appendix B. Battery SOC estimator}

The battery SOC gives the estimation, in percentage, of the amount of energy stored in the ESS related to its rated capacity. The current battery SOC can be estimated as follows [51,49,47,48,68]: 


$$
\operatorname{SOC}(n)=\operatorname{SOC}(n-1)-\Delta \operatorname{SOC}(n),
$$

where the indices $n$ and $(n-1)$ represent the current and previous samples, respectively; and, $\triangle S O C$ is the battery SOC variation, in percentage, during the sampling period $T_{s}$. In addition, $\triangle S O C$ can be estimated using the general definition of the energy evolution $\Delta E_{i}$ of a power variable $P_{i}$ along a time period $\Delta T$. Therefore, assuming equal integration and sampling periods (i.e. $\Delta T=T_{s}$ ), the percentage of the battery SOC variation for sampled variables, $\triangle S O C(n)$, can be expressed as follows $[49,47,48]$ :

$$
\begin{gathered}
\Delta E_{i}(t)=\int_{t}^{t+\Delta T} P_{i}(\tau) d \tau, \\
\Delta S O C(n)=\frac{100}{C_{B A T}} \cdot \int_{(n-1) T_{s}}^{n T_{s}} \eta \cdot P_{B A T}(\tau) d \tau=\frac{100}{C_{B A T}} \cdot \eta \cdot P_{B A T}(n-1) \cdot T_{s},
\end{gathered}
$$

where $C_{B A T}$ is the battery rated capacity, and $\eta$ is the battery efficiency, which considers different efficiencies for battery charging and discharging processes, namely:

$$
\eta=\left\{\begin{array}{c}
1 / \eta_{D}, \quad \forall P_{B A T}>0 \\
\eta_{C}, \forall P_{B A T}<0
\end{array},\right.
$$

being $\eta_{D}$ and $\eta_{C}$ the battery discharge and charge efficiencies, respectively.

In addition, with the aim of preserving the battery lifetime, the available battery capacity should be kept within secure limits at any time. Therefore, a maximum Depth of Discharge (DOD) of 50\% is considered in this study [69]. The battery constraints are expressed as follows [49,47,48]:

$$
\begin{aligned}
& S O C_{M I N} \leq S O C(n) \leq S O C_{M A X}, \\
& S O C_{M I N}=(1-D O D) \cdot S O C_{M A X},
\end{aligned}
$$

where $S O C_{M I N}$ and $S O C_{M A X}$ are the minimum and maximum battery SOC limits, respectively. Note that in order to avoid discharging/overcharging the battery out of the secure limits, the energy management strategy should cut-off the power delivered/absorbed by the battery. In those cases $P_{B A T}=0$, or equivalently according to (1), $P_{G R I D}=P_{L G}$, which means that all power fluctuations will be handled by the grid [47].

\section{References}

[1] Kanchev H, Lu D, Colas F, Lazarov V, Francois B. Energy Management and Operational Planning of a Microgrid With a PV-Based Active Generator for Smart Grid Applications. IEEE Trans Ind Electron 2011;58:4583-92.

[2] Rahbar K, Xu J, Zhang R. Real-Time Energy Storage Management for Renewable Integration in Microgrid: An Off-Line Optimization Approach. IEEE Trans Smart Grid 2015;6:124-34.

[3] Basak P, Chowdhury S, Halder nee Dey S, Chowdhury SP. A literature review on integration of distributed energy resources in the perspective of control, protection and stability of microgrid. Renew Sustain Energy Rev 2012;16:5545-56.

[4] Huang W, Lu M, Zhang L. Survey on Microgrid Control Strategies. Energy Procedia 2011;12:206-12.

[5] Unamuno E, Barrena JA. Hybrid ac/dc microgrids—Part I: Review and classification of topologies. Renew Sustain Energy Rev 2015;52:1251-9.

[6] Olivares DE, Mehrizi-Sani A, Etemadi AH, Cañizares C a., Iravani R, Kazerani M, et al. Trends in microgrid control. IEEE Trans Smart Grid 2014;5:1905-19.

[7] Katiraei F, Iravani R, Hatziargyriou N, Dimeas A. Microgrids management. IEEE Power Energy 
Mag 2008;6:54-65.

[8] Bouzid AM, Guerrero JM, Cheriti A, Bouhamida M, Sicard P, Benghanem M. A survey on control of electric power distributed generation systems for microgrid applications. Renew Sustain Energy Rev 2015;44:751-66.

[9] Lasseter RH. MicroGrids. IEEE Power Eng. Soc. Winter Meet., vol. 1, New York, NY, EEUU: 2002, p. 305-8.

[10] Hatziargyriou N. Microgrids: Architectures and Control. Chichester, UK: Wiley; 2014.

[11] Hatziargyriou N, Asano H, Iravani R, Marnay C. Microgrids. IEEE Power Energy Mag 2007;5:78-94.

[12] Soshinskaya M, Crijns-Graus WHJ, Guerrero JM, Vasquez JC. Microgrids: Experiences, barriers and success factors. Renew Sustain Energy Rev 2014;40:659-72.

[13] Liu B, Zhuo F, Zhu Y, Yi H. System Operation and Energy Management of a Renewable EnergyBased DC Micro-Grid for High Penetration Depth Application. IEEE Trans Smart Grid 2015;6:1147-55.

[14] Su W, Wang J. Energy Management Systems in Microgrid Operations. Electr J 2012;25:45-60.

[15] Jiang Q, Xue M, Geng G. Energy Management of Microgrid in Grid-Connected and Stand-Alone Modes. IEEE Trans Power Syst 2013;28:3380-9.

[16] Urtasun A, Barrios EL, Sanchis P, Marroyo L. Frequency-Based Energy-Management Strategy for Stand-Alone Systems With Distributed Battery Storage. IEEE Trans Power Electron 2015;30:4794-808.

[17] Kyriakarakos G, Piromalis DD, Dounis AI, Arvanitis KG, Papadakis G. Intelligent demand side energy management system for autonomous polygeneration microgrids. Appl Energy 2013;103:39-51.

[18] Marzband M, Ghadimi M, Sumper A, Domínguez-García JL. Experimental validation of a realtime energy management system using multi-period gravitational search algorithm for microgrids in islanded mode. Appl Energy 2014;128:164-74.

[19] Marzband M, Parhizi N, Adabi J. Optimal energy management for stand-alone microgrids based on multi-period imperialist competition algorithm considering uncertainties: experimental validation. Int Trans Electr Energy Syst 2016;26:1358-72.

[20] Marzband M, Sumper A, Domínguez-García JL, Gumara-Ferret R. Experimental validation of a real time energy management system for microgrids in islanded mode using a local day-ahead electricity market and MINLP. Energy Convers Manag 2013;76:314-22.

[21] Marzband M, Sumper A, Ruiz-Álvarez A, Domínguez-García JL, Tomoiagă B. Experimental evaluation of a real time energy management system for stand-alone microgrids in day-ahead markets. Appl Energy 2013;106:365-76.

[22] Palma-Behnke R, Benavides C, Lanas F, Severino B, Reyes L, Llanos J, et al. A Microgrid Energy Management System Based on the Rolling Horizon Strategy. IEEE Trans Smart Grid 2013;4:996-1006.

[23] Malysz P, Sirouspour S, Emadi A. An Optimal Energy Storage Control Strategy for Gridconnected Microgrids. IEEE Trans Smart Grid 2014;5:1785-96.

[24] Yazdanian M, Mehrizi-Sani A. Distributed Control Techniques in Microgrids. IEEE Trans Smart Grid 2014;5:2901-9.

[25] Arul PG, Ramachandaramurthy VK, Rajkumar RK. Control strategies for a hybrid renewable energy system: A review. Renew Sustain Energy Rev 2015;42:597-608.

[26] Guerrero JM, Vasquez JC, Matas J, de Vicuna LG, Castilla M. Hierarchical Control of DroopControlled AC and DC Microgrids-A General Approach Toward Standardization. IEEE Trans Ind Electron 2011;58:158-72.

[27] Palizban O, Kauhaniemi K, Guerrero JM. Microgrids in active network management—Part I: 
Hierarchical control, energy storage, virtual power plants, and market participation. Renew Sustain Energy Rev 2014;36:428-39.

[28] Unamuno E, Barrena JA. Hybrid ac/dc microgrids—-Part II: Review and classification of control strategies. Renew Sustain Energy Rev 2015;52:1123-34.

[29] Tran D, Khambadkone AM. Energy Management for Lifetime Extension of Energy Storage System in Micro-Grid Applications. IEEE Trans Smart Grid 2013;4:1289-96.

[30] Marinelli M, Sossan F, Costanzo GT, Bindner HW. Testing of a Predictive Control Strategy for Balancing Renewable Sources in a Microgrid. IEEE Trans Sustain Energy 2014;5:1426-33.

[31] Anvari-Moghaddam A, Monsef H, Rahimi-Kian A. Optimal Smart Home Energy Management Considering Energy Saving and a Comfortable Lifestyle. IEEE Trans Smart Grid 2015;6:324-32.

[32] Pascual J, Sanchis P, Marroyo L. Implementation and Control of a Residential Electrothermal Microgrid Based on Renewable Energies, a Hybrid Storage System and Demand Side Management. Energies 2014;7:210-37.

[33] Tascikaraoglu A, Boynuegri AR, Uzunoglu M. A demand side management strategy based on forecasting of residential renewable sources: A smart home system in Turkey. Energy Build 2014;80:309-20.

[34] Wang D, Ge S, Jia H, Wang C, Zhou Y, Lu N, et al. A Demand Response and Battery Storage Coordination Algorithm for Providing Microgrid Tie-Line Smoothing Services. IEEE Trans Sustain Energy 2014;5:476-86.

[35] Prodan I, Zio E. A model predictive control framework for reliable microgrid energy management. Int J Electr Power Energy Syst 2014;61:399-409.

[36] Bruni G, Cordiner S, Mulone V, Rocco V, Spagnolo F. A study on the energy management in domestic micro-grids based on Model Predictive Control strategies. Energy Convers Manag 2015;102:50-8.

[37] Passino K, Yurkovich S. Fuzzy Control. Addisson-Wesley, 2010, p. 55-1-55-27.

[38] Serraji M, Boumhidi J, Nfaoui EH. MAS energy management of a microgrid based on fuzzy logic control. 2015 Intell. Syst. Comput. Vis., IEEE; 2015, p. 1-7.

[39] Chen Y-K, Wu Y-C, Song C-C, Chen Y-S. Design and Implementation of Energy Management System With Fuzzy Control for DC Microgrid Systems. IEEE Trans Power Electron 2013;28:1563-70.

[40] Korkas CD, Baldi S, Michailidis I, Kosmatopoulos EB. Occupancy-based demand response and thermal comfort optimization in microgrids with renewable energy sources and energy storage. Appl Energy 2016;163:93-104.

[41] Korkas CD, Baldi S, Michailidis I, Kosmatopoulos EB. Intelligent energy and thermal comfort management in grid-connected microgrids with heterogeneous occupancy schedule. Appl Energy 2015;149:194-203.

[42] Pascual J, Barricarte J, Sanchis P, Marroyo L. Energy management strategy for a renewablebased residential microgrid with generation and demand forecasting. Appl Energy 2015;158:1225.

[43] Seul-Ki Kim, Jin-Hong Jeon, Chang-Hee Cho, Jong-Bo Ahn, Sae-Hyuk Kwon. Dynamic Modeling and Control of a Grid-Connected Hybrid Generation System With Versatile Power Transfer. IEEE Trans Ind Electron 2008;55:1677-88.

[44] Zhou H, Bhattacharya T, Tran D, Siew TST, Khambadkone AM. Composite Energy Storage System Involving Battery and Ultracapacitor With Dynamic Energy Management in Microgrid Applications. IEEE Trans Power Electron 2011;26:923-30.

[45] Barricarte JJ, Martín IS, Sanchis P, Marroyo L. Energy Management Strategies For Grid Integration Of Microgrids Based On Renewable Energy Sources. 10th Int. Conf. Sustain. Energy Technol., Istambul, Turkey: 2011, p. 4-7.

[46] Aviles DA, Guinjoan F, Barricarte J, Marroyo L, Sanchis P, Valderrama H. Battery management 
fuzzy control for a grid-tied microgrid with renewable generation. Proc. IECON 38th Annu. Conf. IEEE Ind. Electron. Soc., Montreal, Canada: IEEE; 2012, p. 5607-12.

[47] Arcos-Aviles D, Pascual J, Marroyo L, Sanchis P, Guinjoan F. Fuzzy Logic-Based Energy Management System Design for Residential Grid-Connected Microgrids. IEEE Trans Smart Grid 2016:1-14.

[48] Arcos-Aviles D, Guinjoan F, Marietta MP, Pascual J, Marroyo L, Sanchis P. Energy management strategy for a grid-tied residential microgrid based on Fuzzy Logic and power forecasting. IECON 2016 - 42nd Annu. Conf. IEEE Ind. Electron. Soc., Florence, Italy: IEEE; 2016, p. 41038.

[49] Arcos-Aviles D, Pascual J, Marroyo L, Sanchis P, Guinjoan F, Marietta MP. Optimal Fuzzy Logic EMS design for residential grid-connected microgrid with hybrid renewable generation and storage. Proc. IEEE 24th Int. Symp. Ind. Electron., Armacao Dos Buzios, Brazil: IEEE; 2015, p. 742-7.

[50] Hanna R, Kleissl J, Nottrott A, Ferry M. Energy dispatch schedule optimization for demand charge reduction using a photovoltaic-battery storage system with solar forecasting. Sol Energy 2014;103:269-87.

[51] Arcos-Aviles D, Espinosa N, Guinjoan F, Marroyo L, Sanchis P. Improved Fuzzy Controller Design for Battery Energy Management in a Grid Connected Microgrid. Proc. IECON 40th Annu. Conf. IEEE Ind. Electron. Soc., Dallas-TX, USA: IEEE; 2014, p. 2128-2133.

[52] Arcos-Aviles D, Vega C, Guinjoan F, Marroyo L, Sanchis P. Fuzzy logic controller design for battery energy management in a grid connected electro-thermal microgrid. Proc. IEEE 23th Int. Symp. Ind. Electron., Istambul, Turkey: IEEE; 2014, p. 2014-9.

[53] Bisschoff WA, Gouws R. Energy management system for a residential grid-tied micro-grid. 2015 Int. Conf. Domest. Use Energy, Cape Town, South Africa: IEEE; 2015, p. 85-91.

[54] Vamos C, Craciun M. Noise Smoothing. In: Vamos C, Craciun M, editors. Autom. Trend Estim., Dordrecht: Springer Netherlands; 2012, p. 43-59.

[55] Solar B. BP585 2002:1-4. http://www.electricsystems.co.nz/documents/BPSolar85w.pdf (accessed July 3, 2016).

[56] Bornay. Aerogenerador Bornay 6000 2010. http://www.bornay.com/media/download/426 (accessed July 3, 2016).

[57] Meteogalicia. Servidor THREDDS de MeteoGalicia n.d. http://www.meteogalicia.es/web/index.action (accessed July 2, 2017).

[58] Foley AM, Leahy PG, Marvuglia A, McKeogh EJ. Current methods and advances in forecasting of wind power generation. Renew Energy 2012;37:1-8.

[59] Yang C, Thatte AA, Xie L. Multitime-Scale Data-Driven Spatio-Temporal Forecast of Photovoltaic Generation. IEEE Trans Sustain Energy 2015;6:104-12.

[60] Zhao B, Zhang X, Chen J, Wang C, Guo L. Operation Optimization of Standalone Microgrids Considering Lifetime Characteristics of Battery Energy Storage System. IEEE Trans Sustain Energy 2013;4:934-43.

[61] Fathima AH, Palanisamy K. Optimization in microgrids with hybrid energy systems - A review. Renew Sustain Energy Rev 2015;45:431-46.

[62] Lorenzo E. Energy Collected and Delivered by PV Modules. In: Luque A, Hegedus S, editors. Handb. Photovolt. Sci. Eng., Chichester, UK, UK: John Wiley \& Sons, Ltd; 2011, p. 984-1042.

[63] Chong WT, Hew WP, Yip SY, Fazlizan A, Poh SC, Tan CJ, et al. The experimental study on the wind turbine's guide-vanes and diffuser of an exhaust air energy recovery system integrated with the cooling tower. Energy Convers Manag 2014;87:145-55.

[64] Manwell JF, McGowan JG, Rogers AL. Wind Energy Explained: Theory, Design and Application, Chichester, UK: John Wiley \& Sons, Ltd; 2009, p. 23-87.

[65] Mathew S. Wind energy : fundamentals, resource analysis and economics, Berlin: Springer; 2006, 
p. 11-88.

[66] Ally C, Bahadoorsingh S, Singh A, Sharma C. A review and technical assessment integrating wind energy into an island power system. Renew Sustain Energy Rev 2015;51:863-74.

[67] Lü X, Lu T, Kibert CJ, Viljanen M. A novel dynamic modeling approach for predicting building energy performance. Appl Energy 2014;114:91-103.

[68] Tazvinga H, Zhu B, Xia X. Optimal power flow management for distributed energy resources with batteries. Energy Convers Manag 2015;102:104-10.

[69] Anuphappharadorn S, Sukchai S, Sirisamphanwong C, Ketjoy N. Comparison the Economic Analysis of the Battery between Lithium-ion and Lead-acid in PV Stand-alone Application. Energy Procedia 2014;56:352-8. 